\title{
The standard addition method and its validation in forensic toxicology
}

\author{
Koutaro Hasegawa $^{1}$ [D $\cdot$ Kayoko Minakata $^{1} \cdot$ Masasko Suzuki $^{1} \cdot$ Osamu Suzuki ${ }^{1}$
}

Received: 8 November 2020 / Accepted: 2 April 2021 / Published online: 4 June 2021

(c) The Author(s) 2021

\begin{abstract}
Purpose In the quantitative forensic toxicological analyses using instruments, major methods to be employed are conventional matrix-matched calibration method (MMCM). However, nowadays, the needs for using the standard addition methods (SAM) are increasing. In spite of this situation, there are no reports of the guidelines for the validations of SAM. In this review, the principle, how to perform it, advantages, disadvantages, reported application data, and the details of validation procedures for the SAM are described.

Methods Various databases such as SciFinder, Google and Google Scholar were utilized to collect relevant reports referring to the SAM. The long experiences of our research group on the SAM were also included in this review.

Results Although the experimental procedures for the SAM are much more laborious than those of the MMCM, the SAM is essential to quantify target xenobiotic(s) in special matrices such as human solid tissues or biles, which remarkably interfere with the usual quantitative analyses. The validation methods for the SAM have been also proposed for the cases in the absence of the blank matrices.

Conclusions To our knowledge, this is the first presentation of detailed SAM procedure and its validation, which will facilitate the use of the SAM in forensic toxicology. Especially for its validation, new simple methods have been proposed.
\end{abstract}

Keywords Standard addition method · Method validation · Guidelines · New psychoactive substances (NPS) - Absence of blank matrix $\cdot$ Surrogate analyte approach

\section{Introduction}

The standard addition method (SAM) has been being used since many years ago for instrumental analysis. According to Burns and Walker [1] and Kelly et al. [2], the first use of the SAM in instrumental chemical analysis was in polarography by Hohn in as early as 1937 . Outside the area of polarography, the SAM was first used in atomic emission spectrometry in 1950, in ultraviolet-visible spectroscopy in 1960, and in ${ }^{1} \mathrm{H}$ nuclear magnetic resonance spectroscopy in 2012 [1]. The theory of SAM in instrumental analyses was published by Bader [3] in 1980. Therefore, the idea of SAM is far from being new; it is a very old but intelligent idea to analyze a compound as accurately as possible.

Koutaro Hasegawa

07484771@hama-med.ac.jp

1 Department of Legal Medicine, Hamamatsu University School of Medicine, 1-20-1 Handayama, Higashi-ku, Hamamatsu 431-3192, Japan
In the field of forensic toxicology, the SAM was first used in 1990s; Siek and Dunn [4] reported a doxylamine overdose death using SAM quantification in 1993, and Poklis et al. [5] reported a fatal suicidal valproic acid overdose in 1998 using the SAM. In those days, it was not necessary for scientists to be nervous to present the validation data of the methods used. Therefore, the detailed method validation data were not demonstrated until early 2000s.

Since the early 2000s, making validations for instrumental analyses have been lively discussed mainly in the U.S. and Europe, and many guideline papers on validation of instrumental analyses have been published in every field of analytical chemistry [6-22]. Currently, when scientists try to publish the result(s) of quantification in an international journal, the presentation of validation data has become mandatory, but they are not necessary for screening tests or semiquantitative experiments. The above guideline papers are exclusively based on the conventional matrix-matched calibration methods (MMCMs), but no papers are available dealing with validation guidelines for the SAM in all analytical chemistry fields including forensic toxicology. 
In 2013, our group published a paper on the presence of several ten to hundred $\mathrm{ng} / \mathrm{mL}$ of ethylene glycol, propylene glycol, and diethylene glycol in whole blood specimens collected from ten healthy subjects [23]. Although high concentrations of ethylene glycol or propylene glycol in blood at more than several hundred $\mu \mathrm{g} / \mathrm{mL}$ in suicidal cases caused by ingesting automobile antifreezes are sometimes encountered in medico-legal cases [24], it was surprising for us to detect them in blood specimens from healthy subjects. The low concentrations of glycols are ubiquitously present even in tap water and atmospheric air. To quantify their concentrations, we had to use SAM, because there were no appropriate blank blood specimens obtainable, which absolutely contained no such glycols. Since then, we have published a considerable number of articles using the SAM together with its validation data [25-42], being included in Table 1. Moreover, we have relatively many opportunities to perform forensic autopsies of cadavers that underwent abuse of new psychoactive substances (NPS). We have conducted studies on the postmortem distribution and redistribution of NPS in various kinds of body fluids and solid tissues to find out the best matrix that contains the highest concentrations of the parent forms or metabolites of NPS, because they are the matters in which the forensic scientists are most interested. To fulfill such distribution studies of toxic compounds over quite different kinds of matrices of cadavers, the SAM seems to be a good choice for accurate quantifications of target compounds.

The aim of this review is to explain the basic methodology of SAM experiments, its advantages and disadvantages, and finally how to present their validation data.

\section{Literature search}

Some databases, such as SciFinder, Google and Google Scholar were utilized to collect relevant reports referring to SAM. Their full texts were carefully checked according to their necessity.

\section{How to get concentration(s) of preexisting xenobiotic(s) in a matrix by the standard addition method}

For the SAM experiments, in the early stage before 2000 , the standard addition with points of only four different concentrations (i.e., three calibrators) were widely employed as the final probe $[1,5,43]$. In our opinion, though it is understandable to use such calibration curves with a few calibration points due to the laboriousness of SAM, the accurateness of such a method is of concern. In addition, when we encounter a case in which the xenobiotic effect is suspected, the identity, level(s) or even order(s) of the target compound(s) are unknown at the beginning; thus we here propose a two-step calibration method. The first step is to check the presence or absence of xenobiotic(s), and if present, to roughly estimate the level(s) of xenobiotic(s) in matrix/matrices. Such information is essential to proceed to the second step for quantification of xenobiotic(s) by SAM.

The first step is simpler the better; thus we have chosen the simplest one-point standard addition test only to check the profile of xenobiotic(s) preexisting in a matrix using only two sample lots for each matrix; $0.2 \mathrm{~g}$ of solid tissue or $0.2 \mathrm{~mL}$ of body fluid is homogenized or diluted to $2.0 \mathrm{~mL}$, respectively. It is divided into two sample lots of the same volume $(1.0 \mathrm{~mL})$. To one of the lots, known amount(s) of the standard(s) of suspected xenobiotic is/are spiked. To another lot, the same volume of water is added. The both sample lots are subjected to pretreatment/extraction procedure and finally instrumental analysis. By such an experiment, it becomes clear whether the matrix contains xenobiotic(s), and if absent, the experiment terminates at the time; if present, the calculation of each concentration $\left(C_{x}\right)$ for each xenobiotic in the diluted matrix can be made as follows (also see Fig. 1):

$C_{x}=\left[P_{0} /\left(P_{\mathrm{a}}-P_{0}\right)\right] \times A_{\mathrm{t}} / W$,

where $P_{0}$ is a peak area or peak height of a xenobiotic preexisting in a homogenate sample lot or a diluted body fluid sample lot without any exogenous addition; $P_{\mathrm{a}}$ is a sum peak area or peak height of the preexisting plus spiked xenobiotic compound; $A_{\mathrm{t}}$ is an amount (i.e., $\mu \mathrm{g}$ or $\mathrm{ng}$ ) of a xenobiotic compound standard spiked into a sample lot; $W$ is g wet weight or $\mathrm{mL}$ of the matrix contained in each sample lot.

In case of multidrug consumption, known amounts of corresponding xenobiotic standard mixture are spiked altogether into one of the two homogenate or diluted body fluid lots; this sample lot together with the corresponding blank sample lot containing the preexisting xenobiotic(s) only is subjected to the pretreatment/extraction, followed by the instrumental analyses as described above. The concentrations of all kinds of xenobiotics can be roughly calculated using the above Eq. (1). If the peak of the non-spiked sample lot is less than $1 / 10$ that of the spiked sample lot, the first step experiment should be again performed from the beginning with reducing the amount(s) of corresponding xenobiotic(s) spiked into one of the two sample lots.

To make the above explanation for the first step experiment easier, the image of the two peaks for the one-point standard addition method conducted at the first step is shown in Fig. 1.

In the second (final) experiment, after homogenization of the tissue specimen ( $1.0 \mathrm{~g}$ wet weight) or dilution of the body fluid specimen $(1.0 \mathrm{~mL})$ to prepare $10 \mathrm{~mL}$ of sample 


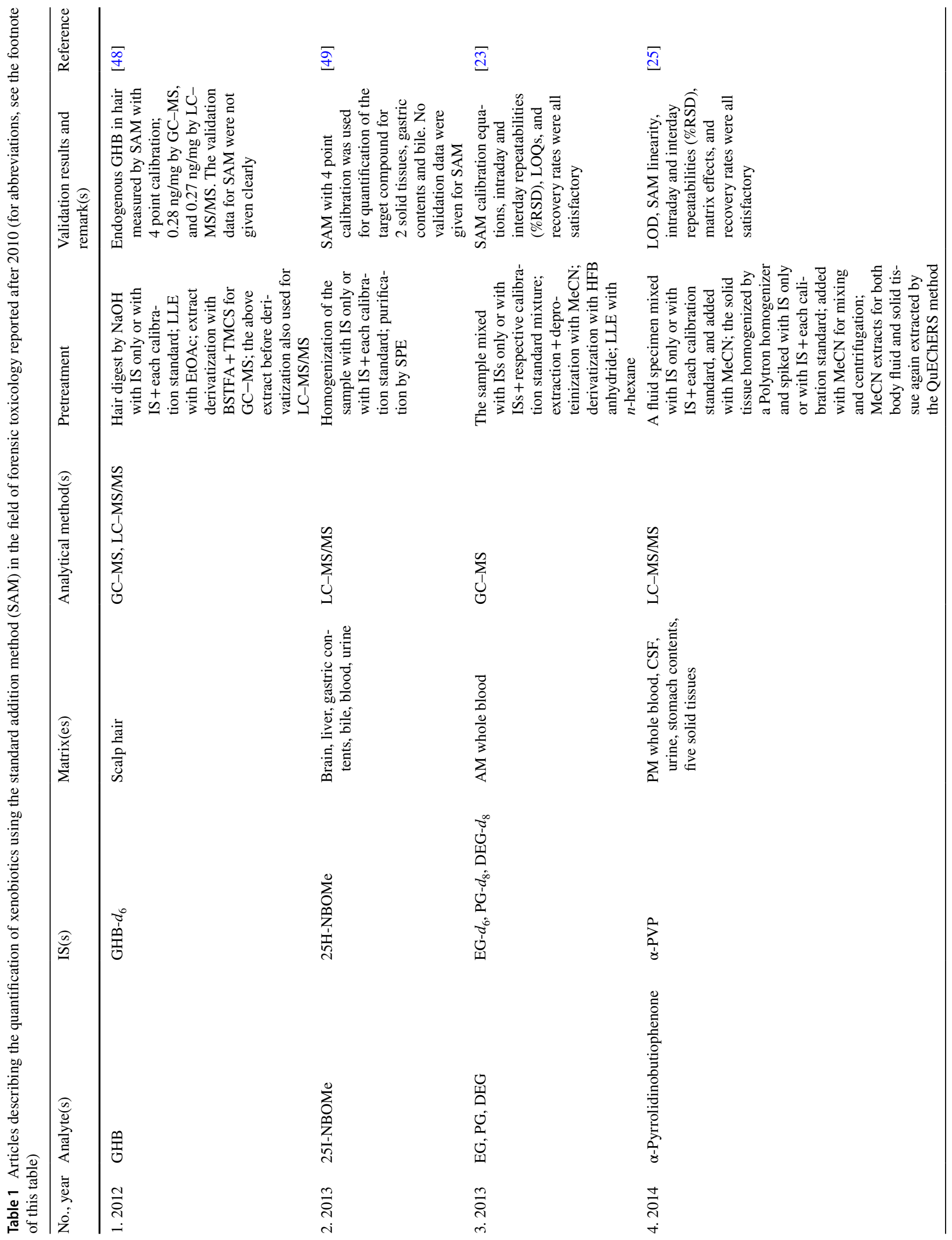




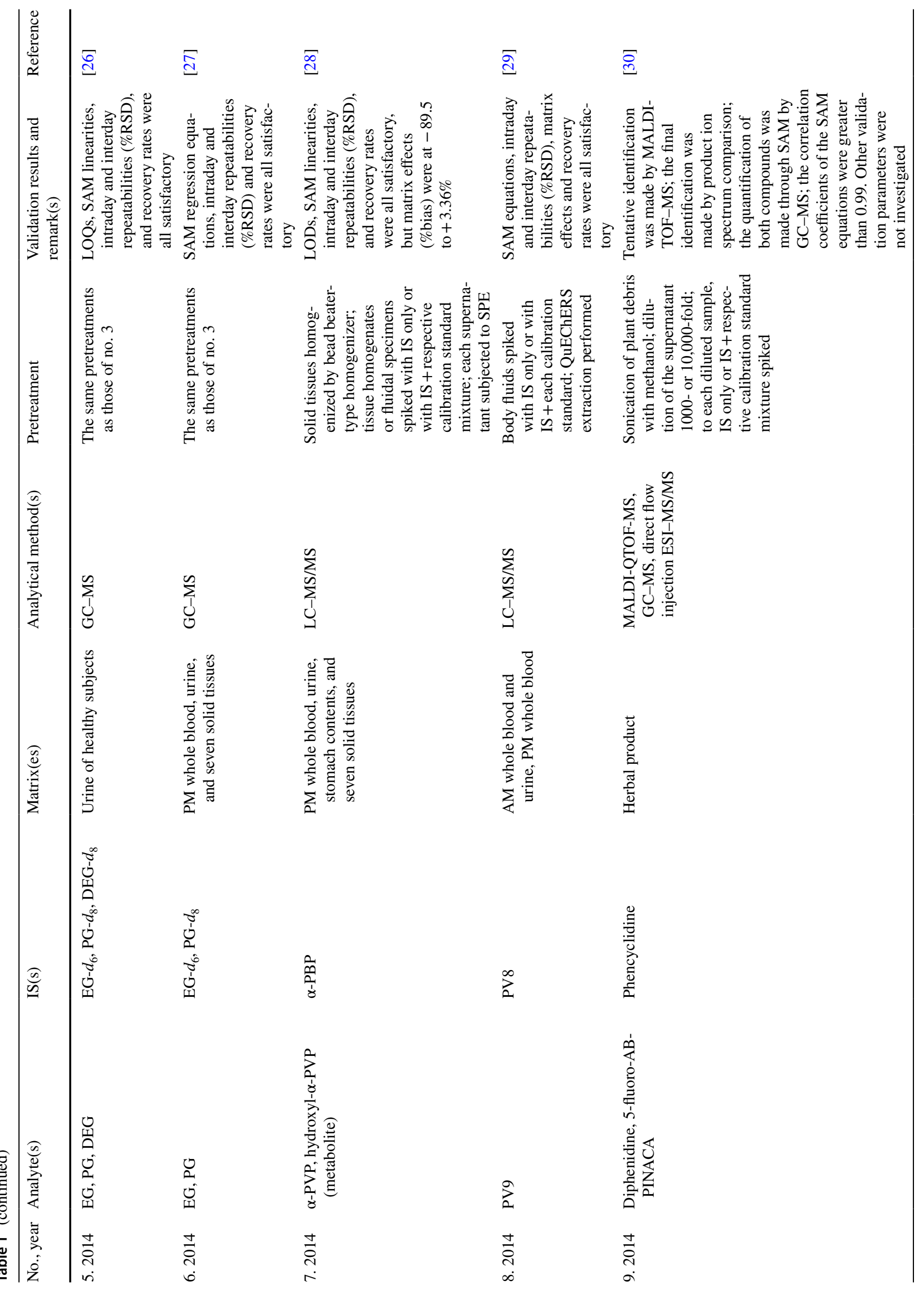




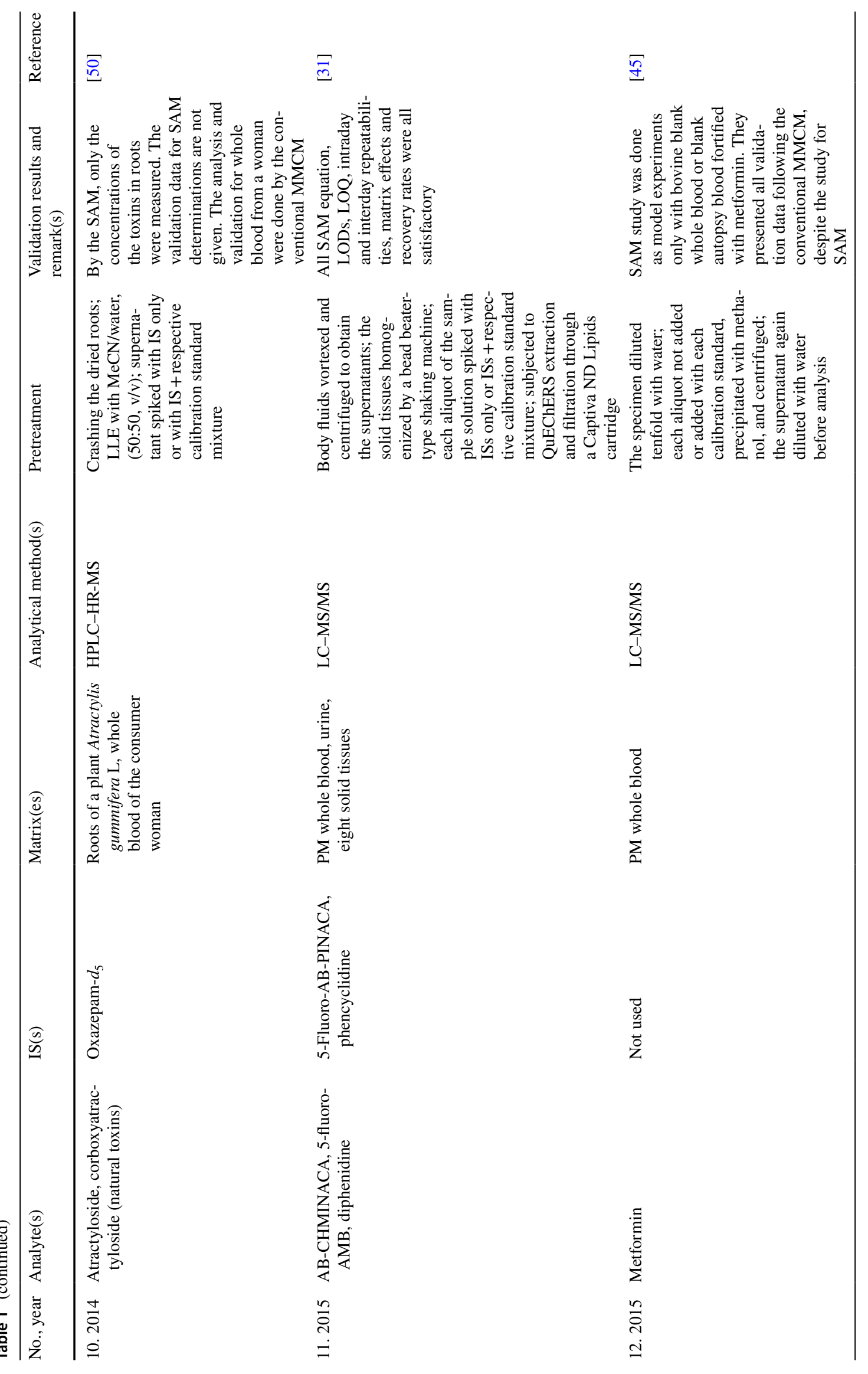




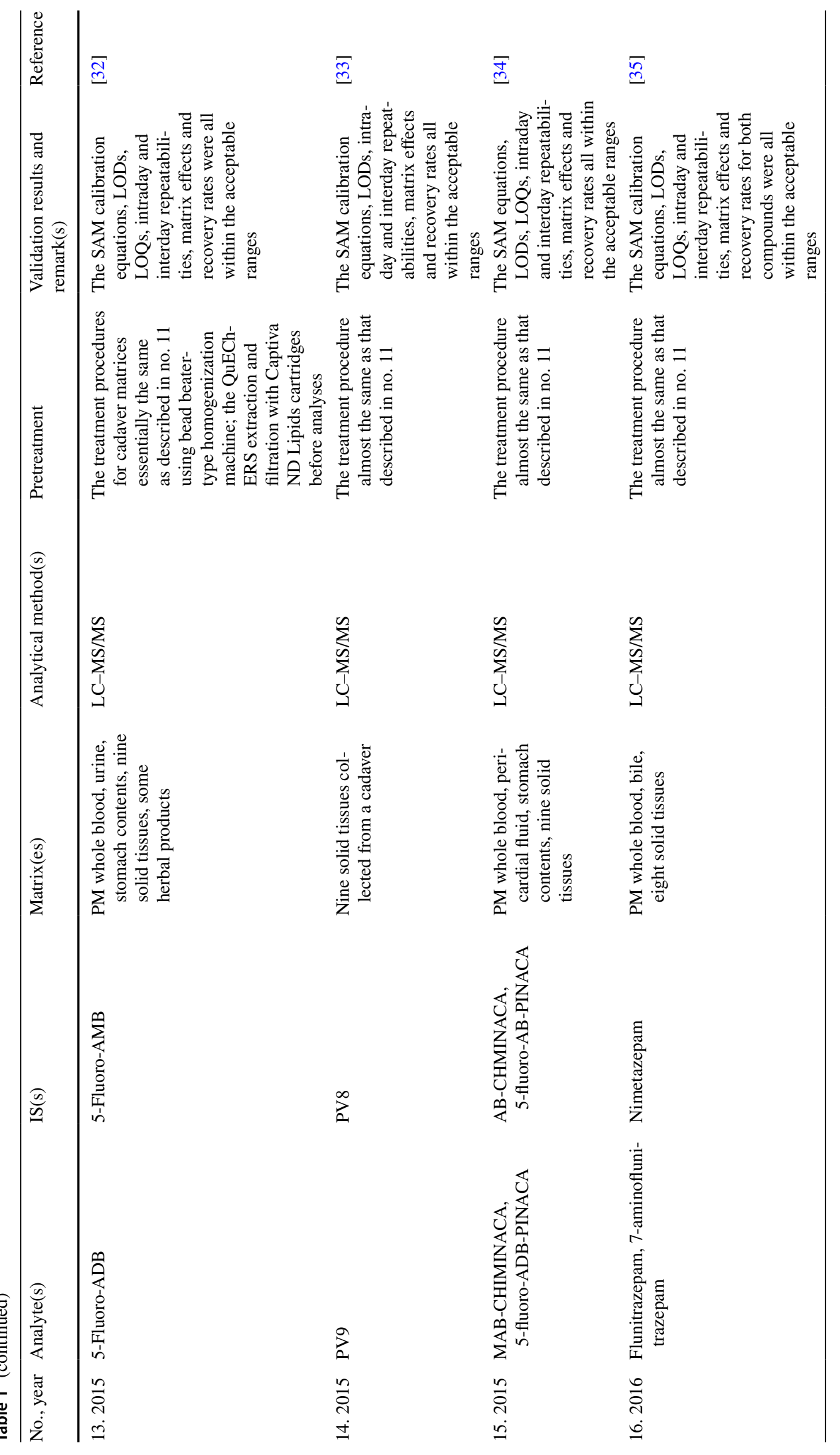




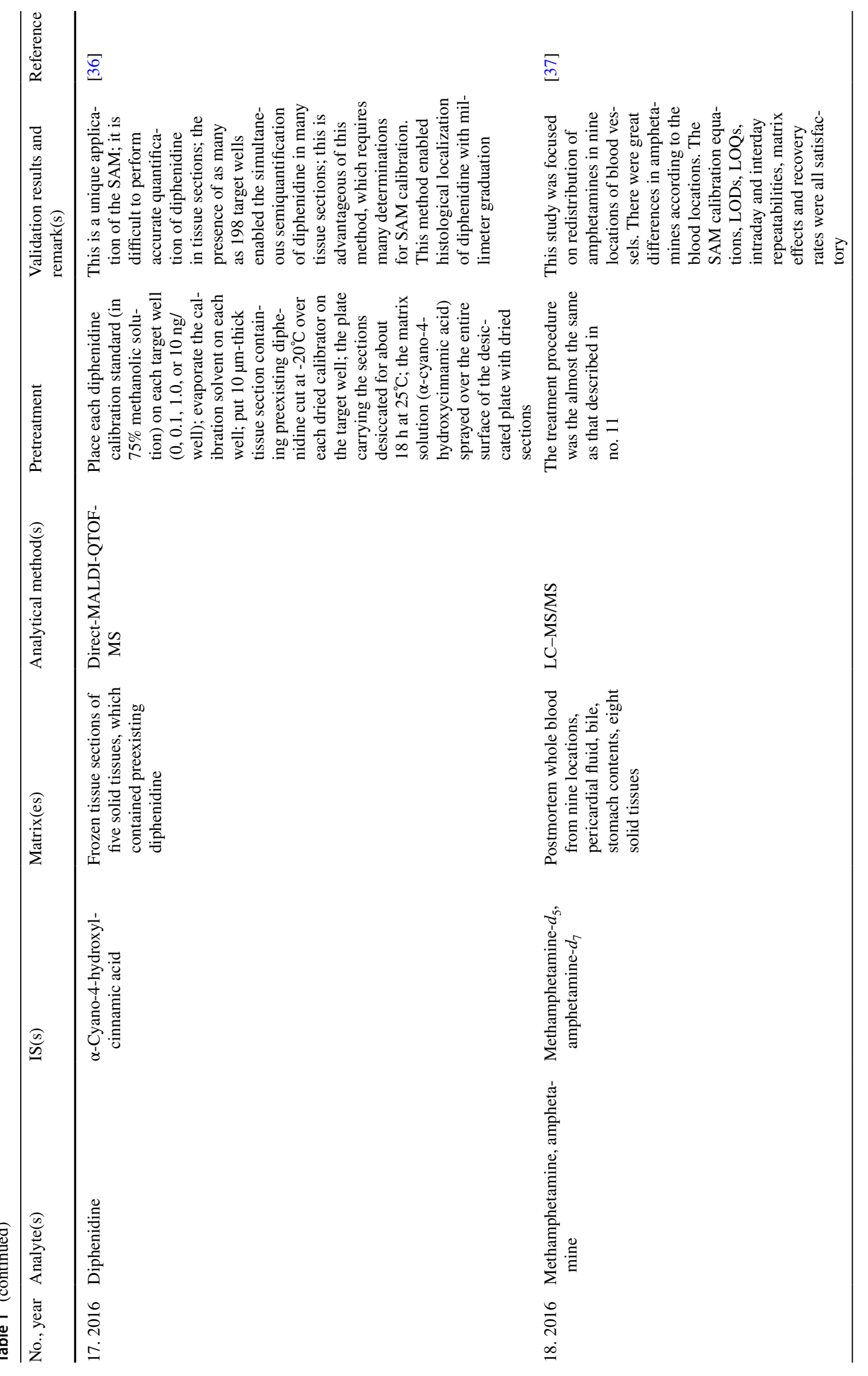




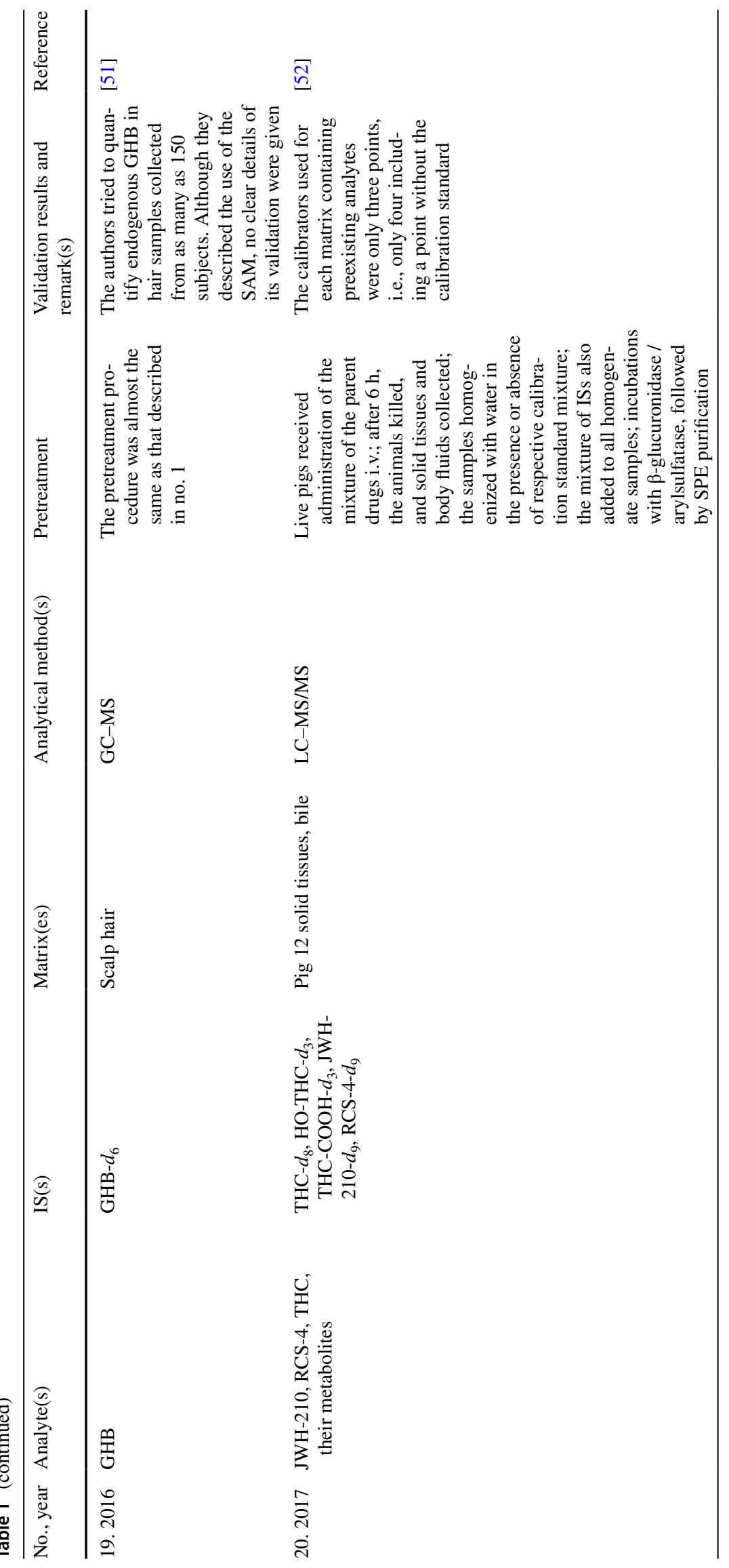




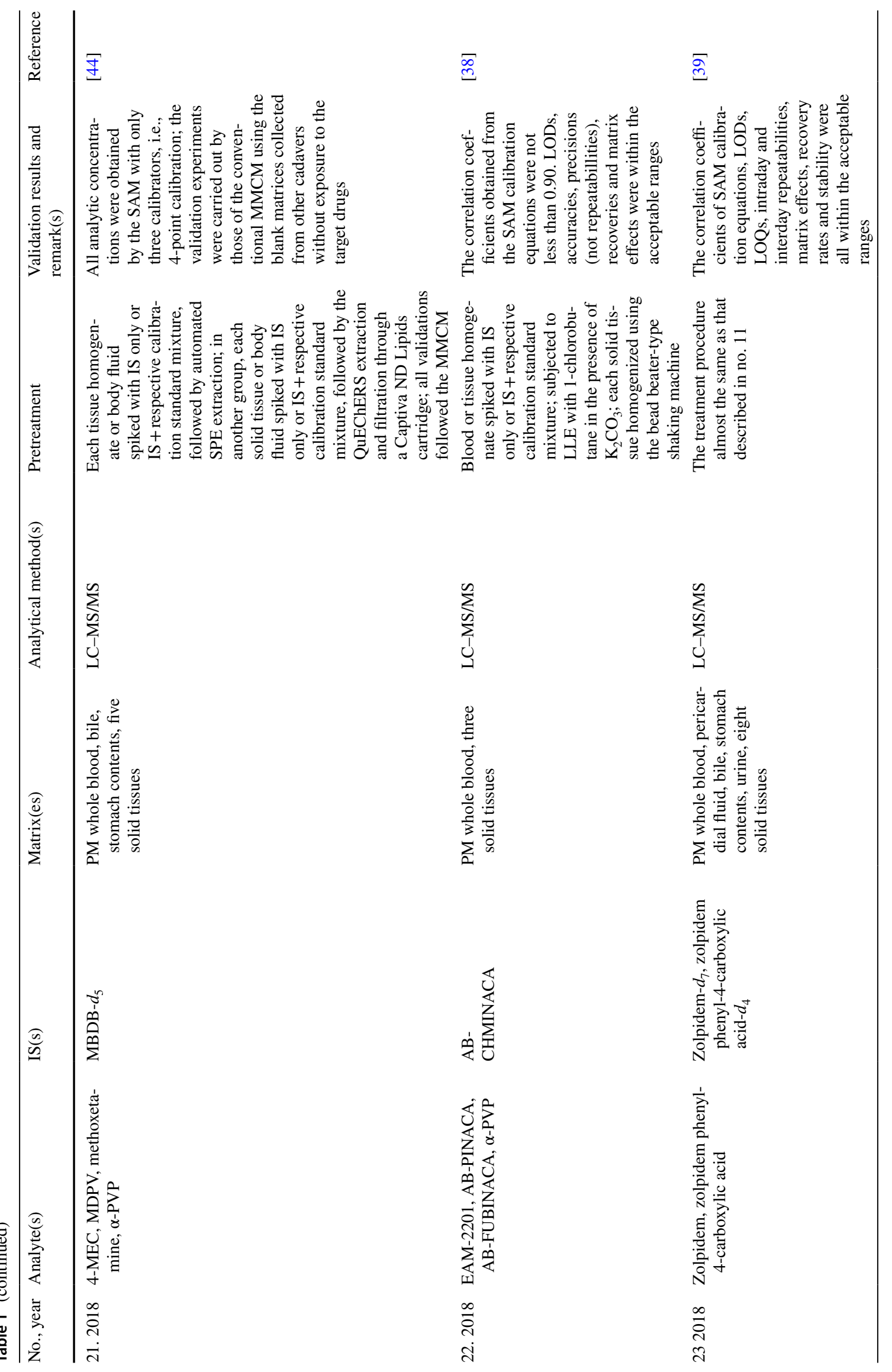




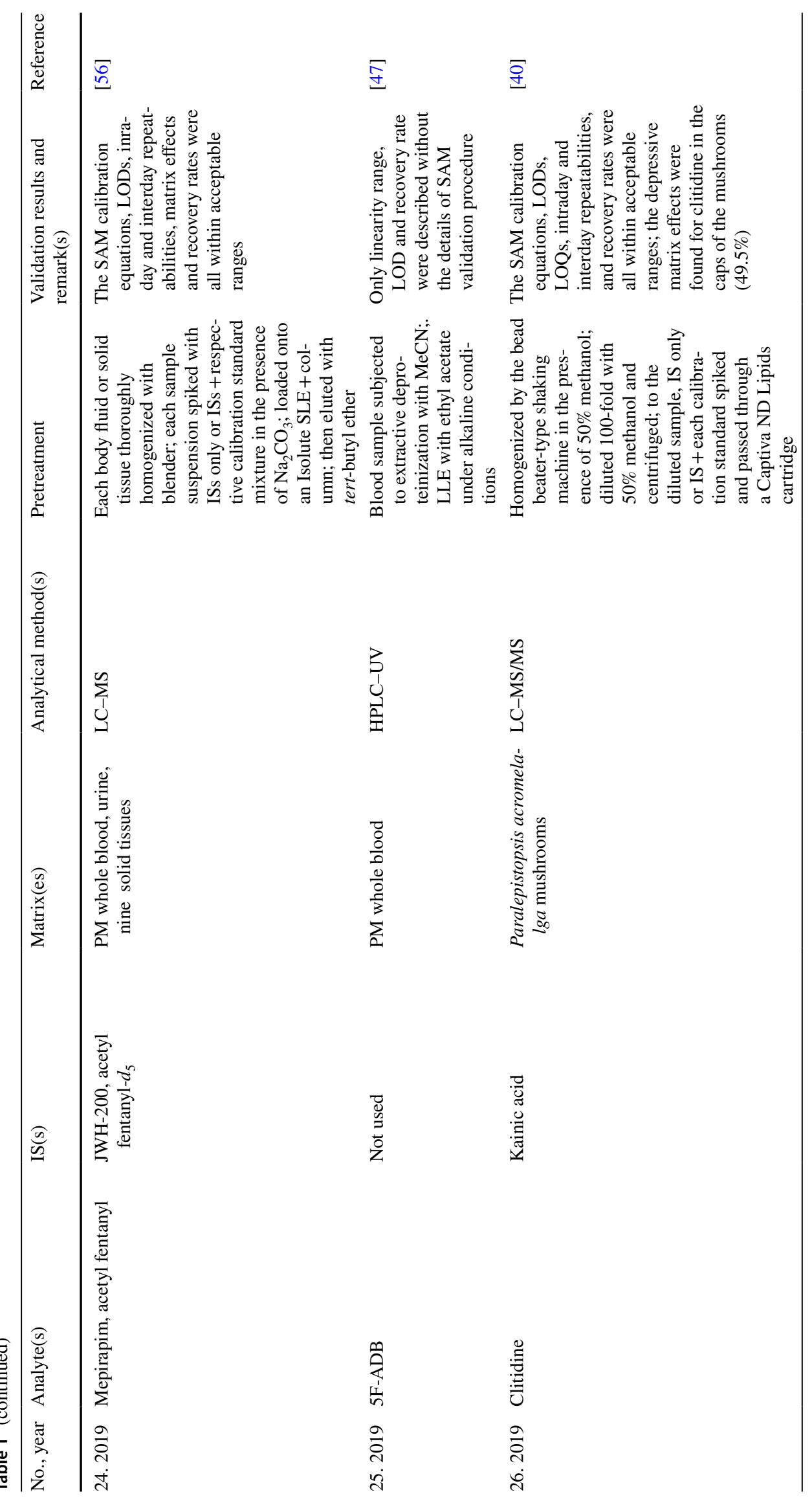




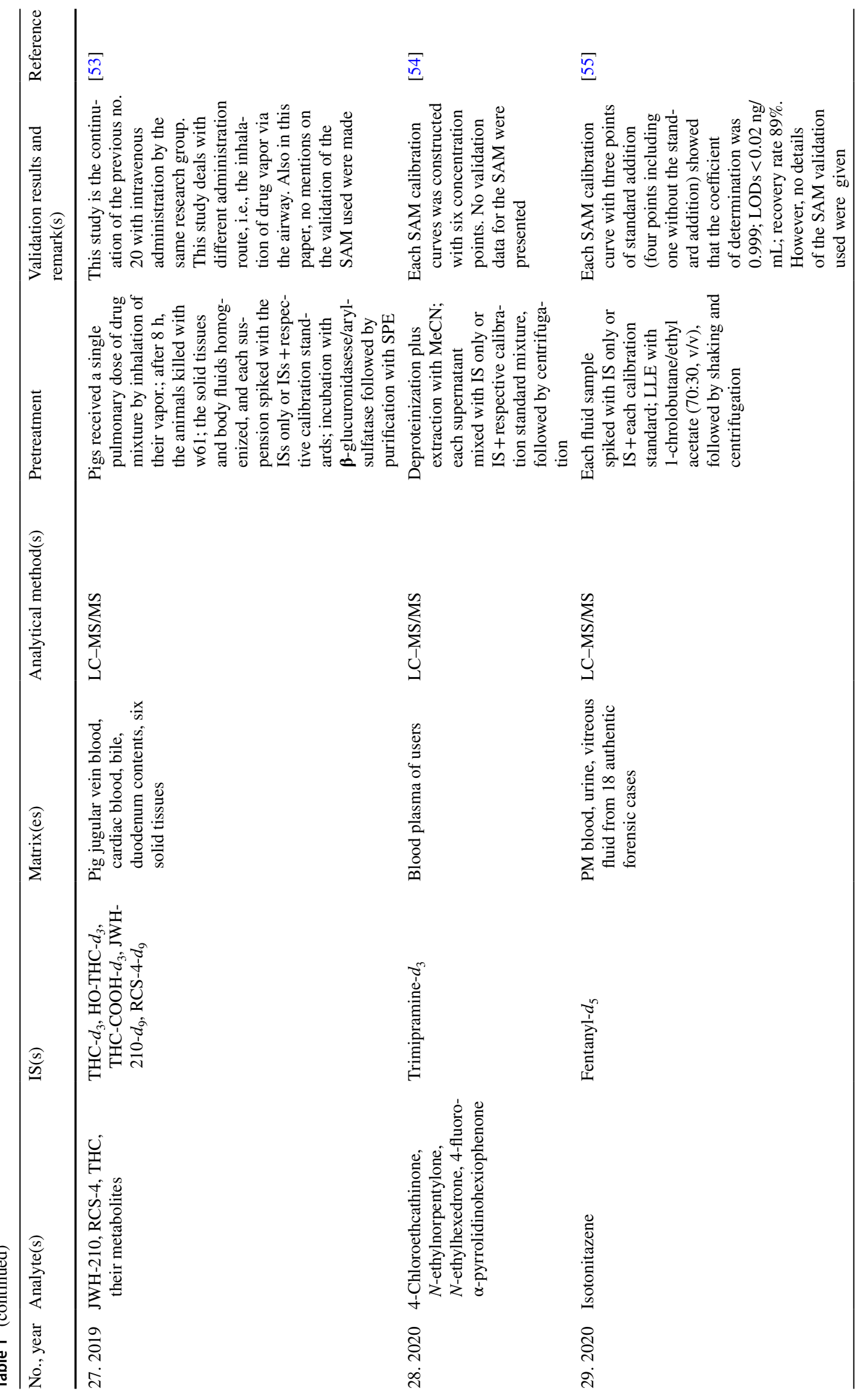




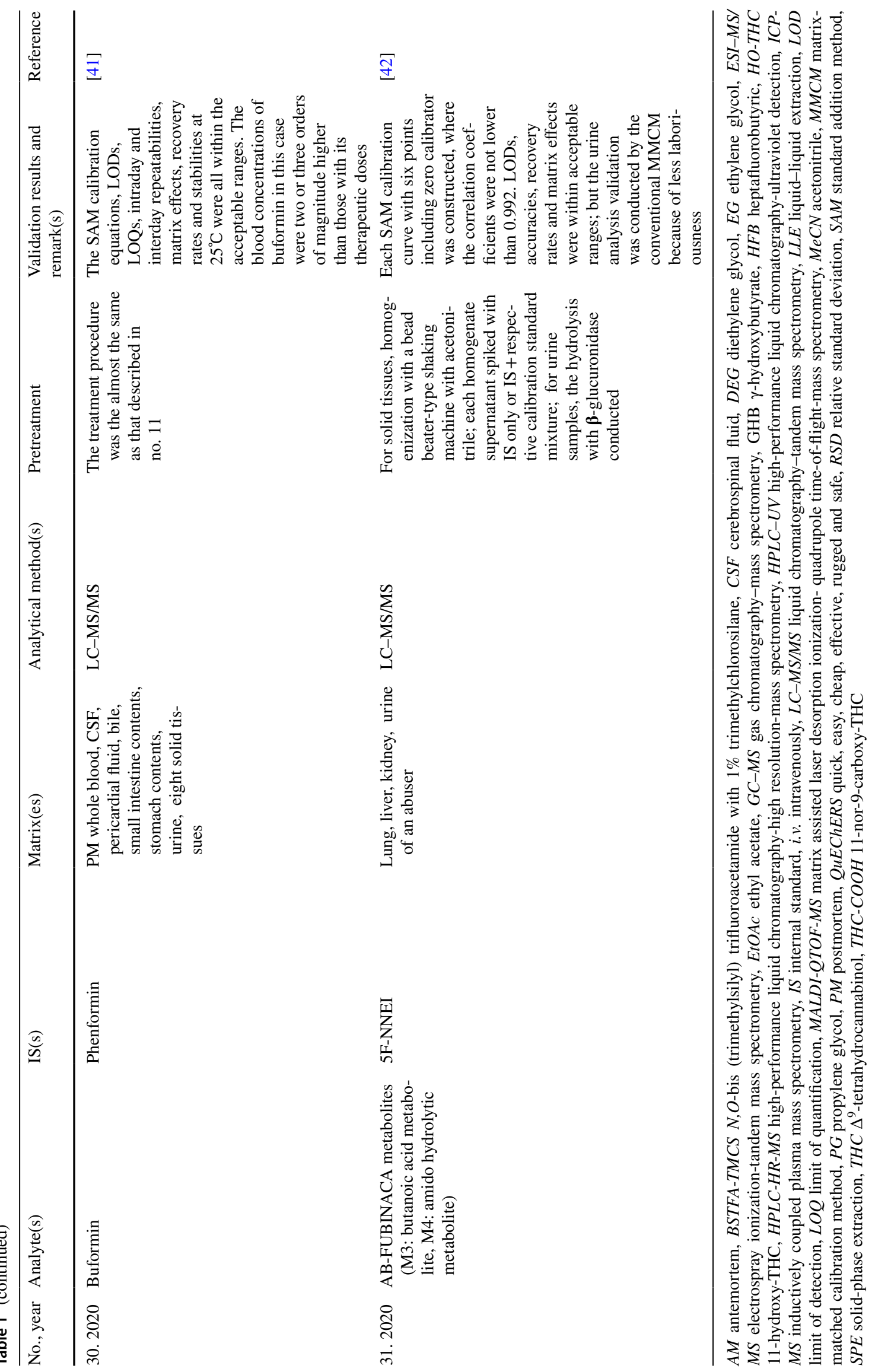


Fig. 1 Image for a one-point standard addition assay as the first step experiment. Pa: a sum of peak area or peak height of the preexisting plus spiked target compound; $\mathrm{P}_{0}$ : peak area or peak height of a target compound preexisting in a matrix

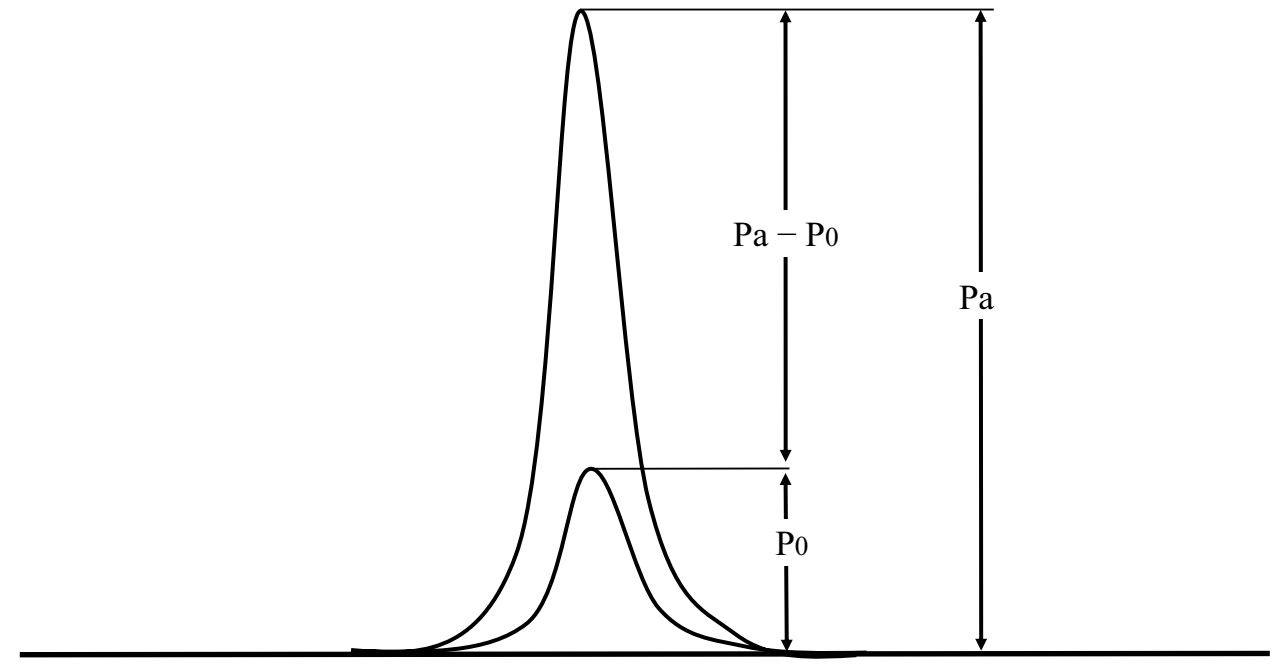

suspension or solution, respectively, a fixed concentration of an internal standard (IS) is added to it to reduce errors during the pipetting manipulation of sample solution volumes and during instability of the target compound(s) and IS inside an analytical instrument. Then, it is divided into ten sample lots of the same volume; six sample lots are used to fulfill the final SAM measurements. The SAM calibration equation is expressed as $y=a x+b$, where " $a$ " is the slope of the curve; " $b$ " is the value of the intercept on the $y$ axis (also see Fig. 2).

To the five sample lots, different concentrations of xenobiotic (target compound) standard(s) are added. Thereby, in case of multidrug consumption, where multidrugs coexist in the same sample lot, it is not necessary to add the same concentration for every multidrug standard to each sample lot to create a SAM calibration curve. The five concentrations with an appropriate range and spaces between points for each xenobiotic standard to be spiked into the five sample lots are separately decided on the basis of information for each concentration of the preexisting drugs obtained by the first step experiment. Therefore, different concentrations of spiked multudrugs can coexist in each sample lot. However, for all of the multidrugs, the concentrations of each drug standard spiked should be aligned in the increasing order from sample lots 1 to 5. The extractions and the instrumental analyses have to be started from one sample lot spiked only with IS without addition of any xenobiotic standard, followed by the one to five sample lots (in total six points for each target compound)
Fig. 2 Various patterns of standard addition calibration curves to obtain an accurate concentration of a target compound. The negative intercept position indicated by closed circle $\left(2 a_{x} \approx b_{x}\right)$ on the $x$ axis shows the concentration of the target compound in preferable pattern. Please note whether the concentration of each target compound is within the range of respective calibrators. open circle (negative intercept $>>b_{x}$ ) and open square (negative intercept $<<b_{x}$ ): non- preferable patterns

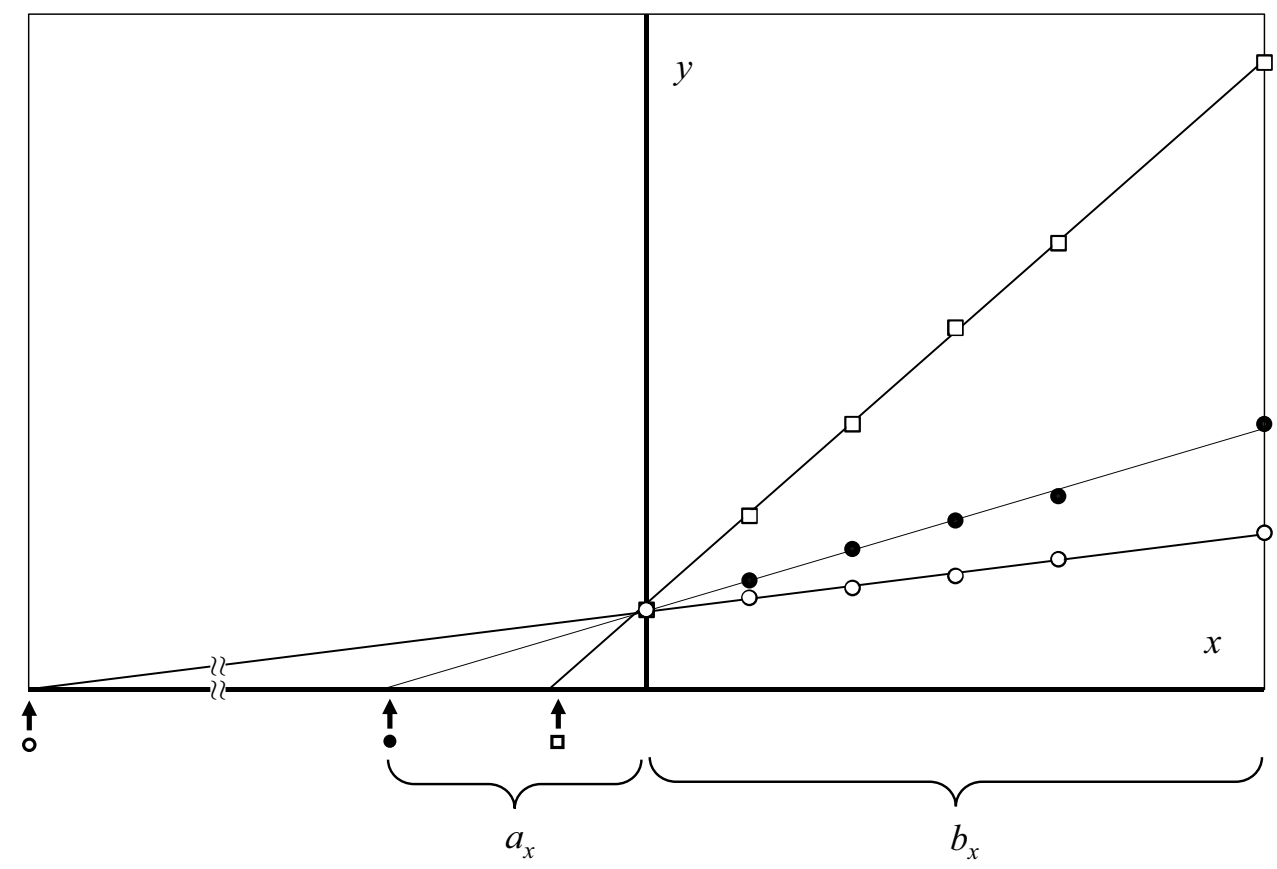


for each matrix. Then a ratio of (peak area of the preexisting xenobiotic compound)/(IS peak area) and five different ratios of (combined peak area of the preexisting xenobiotic compound plus each different concentration of the same xenobiotic compound spiked)/(IS peak area) are plotted against the concentration on the horizontal axis for each xenobiotic in the matrix. Along the six points, a straight line is drawn by the least square method. The straight line intercepts the horizontal axis in the negative range, which gives the preexisting concentration of each xenobiotic compound in the tissue matrix (/g wet weight) or in the body fluid matrix $(/ \mathrm{mL})$ (Fig. 2). If four kinds of drugs coexist in a matrix, four calibration curves with six points can be drawn to give four concentrations of the multidrugs in the matrix. This means that the concentrations of multiple preexisting xenobiotics in a matrix can be obtained by the simultaneous analysis with only six sample lots for each matrix.

The remaining four sample lots $(4.0 \mathrm{~mL})$ containing a fixed concentration of IS plus preexisting xenobiotic(s) are used for the validation experiments, which will be explained later.

It should be mentioned here that the IS can be omitted (see Table 1, nos. 12 and 25), and the procedure can be performed only with peak areas or peak heights (instrumental units of them) of the preexisting compound(s) and spiked calibrators. An appropriate IS is added to a matrix sample only to reduce errors as stated above. The best IS is the target compound itself labelled with stable isotopic atoms.

In our group, we usually create the SAM regression equations with five different concentrations of calibrators (totally six points including the no addition point). Although the accurateness of the experiment depends on the skillfulness of an experimenter, the patterns of the calibration curves (Fig. 2) also affect the accurateness of the quantification, because each value of the preexisting xenobiotic concentration should be located within the corresponding $b_{x}$ calibrator concentration range and preferably close to the midst of the range. When the three patterns of SAM calibration curves are compared, the curve indicated by closed circle pattern in Fig. 2 probably gives the most accurate result; in other curve patterns indicated by open circle (negative intercept $>>b_{x}$ ) and by open square (negative intercept $<<b_{x}$ ), the obtained concentrations of the target compound are outside of the calibration range, and the errors in drawing each calibration curve will cause a significant shift of the intercept location on the negative horizontal axis resulting in relatively larger variations of the xenobiotic concentrations.

\section{Advantages and disadvantages of the standard addition method}

The first advantage to be mentioned for SAM is that it does not need a blank matrix (surrogate matrix) for quantification of a target compound. In the conventional MMCM, to construct a calibration curve, different amounts of each target compound should be spiked into suitable blank matrix [7-20]. However, strictly speaking, for example, the components in blood specimen collected from a cadaver are not the same or not even similar as compared to those of fresh blood collected from healthy volunteers; furthermore, there are individual differences of blood components due to different age, sex, constitution, body mass index/obesity, and the presence and absence of disorder(s) for each cadaver, and most importantly the postmortem change/decomposition for the cadaver results in marked changes in components of blood. Also for solid tissues/ organs, their components are quite different according to individual differences; for validation of quantification of a life-threatening chemical or its metabolite in solid tissue, Lehmann et al. [44] quantified NPS in various body fluids and solid tissues collected at autopsy by SAM, but used blank matrices from different cadavers that were completely free of NPS exposure to perform validation tests according to the MMCM. However, it is questionable that the quantitative results obtained by SAM are strictly equal to the data obtained by MMCM.

In many institutions in Japan, the institutional review board does not approve of using forensic cadavers for getting blank matrices; they usually insist that the cadavers should be used only for investigating the direct or indirect cause(s) of deaths, and criticize the use of cadavers as blank specimens only. This is the main reason for our research group to use SAM for quantification of xenobiotics in cadaver samples collected at autopsy. However, in most advanced countries, there are no such high barriers to use autopsy samples for medical research purposes.

As the second advantage, the SAM overcomes the matrix effects and recovery rates. The obtained values are free of matrix effects and recovery rates. Gergov et al. [45] reported that SAM was very effective for overcoming the matrix effects on metformin caused by postmortem blood samples. It is true that SAM really overcomes the matrix effects and recovery rates, but other methods to overcome the matrix effects should be mentioned; most effective one is to use a stable isotope-labeled IS of a target compound, and another one is to use a highly effective extraction/purification pretreatment such as the QuEChERS method [25]. In addition, in this review, we have tried to devise new simple calculation methods of matrix effects and recovery rates for SAM, which are also explained later. The 
quantification of drugs in solid tissues by liquid chromatography-tandem mass spectrometry (LC-MS/MS) is most sensitive to matrix effects. The SAM is very useful for the LC-MS/MS quantification of compound(s) contained in solid tissues frequently causing serious matrix effects by the conventional MMCM.

As the third advantage of the SAM, when an appropriate IS (stable isotope-labelled compound of the target compound or the different one but is very close physicochemically) is not available, the quantification can be fulfilled without IS [45-47]. As stated before, in the SAM, the presence of IS is not essential, but only contributes to reduction of errors in assays.

As the main disadvantage of the SAM, the laboriousness of the experiments should be mentioned. Even to quantify a single concentration of a xenobiotic in a matrix, two peaks with and without addition of a known amount of the target compound standard should be obtained as the first step experiment (Fig. 1). Then to perform accurate quantification of preexisting compound(s), the second step experiment is needed as already shown in Fig. 2. The first step one is rough estimation of unknown level(s) of the xenobiotic(s); another is for accurate quantification with six points. If the experiment is repeated in duplicate or triplicate, the labor increases twice or three times, respectively.

According to the larger number of experiments to be done in the SAM, larger amounts of matrix containing target xenobiotic(s) become necessary [e.g., more than $1.0 \mathrm{~mL}$ of body fluids, and more than $1.0 \mathrm{~g}$ of solid tissues containing target compound(s)]. This is also a disadvantage of SAM. However, such a problem is being solved because the sensitivities of analytical instruments have markedly increased during the past 10 years, resulting in that much less amounts of matrices have become sufficient to complete the experiments currently.

\section{Validation for the standard addition method}

The conventional MMCM and SAM are fundamentally different. In the MMCM, the calibration curve is constructed by adding different concentrations of a xenobiotic standard together with IS to divided lots of blank matrix fluid or blank tissue homogenate for creating the calibrators. This means that the validation is not focused on the original sample matrix in question, but focused on the blank matrix, which may be similar to but not the same as the original sample matrix, while in the SAM, IS only and IS plus different concentrations of the xenobiotic(s) are spiked into divided sample lots composed of each real matrix fluid or homogenate (sometimes undiluted or diluted) containing the preexisting xenobiotic(s) to make calibrators before extraction procedure. The SAM validations are conducted on the target matrices, and not on the blank matrices being used in the MMCM.

In recent years, it seems likely that scientific reports using SAM are increasing, but in many of them except our reports, the validation data for SAM are either missing, incomplete or confusingly mixed with the validations of MMCM [48-55] (see Table 1). Only one report [56] describing postmortem distribution of mepirapim and acetyl fentanyl in a cadaver that died of drug poisoning presented satisfactory validation data for SAM, which were similar to those proposed by our group [25, 28, 31-35, 37, 39].

We think that although many of forensic toxicologists are interested in the SAM, they are usually not so familiar with how to present validation data for studies or case reports using SAM. In the following sections, we describe details of how to present the validation data of SAM.

\section{Standard addition calibration regression equations and correlation coefficients}

As shown in Fig. 2, by adding different concentrations of xenobiotic(s) to divided sample lots of diluted body fluid or tissue homogenates containing the preexisting xenobiotic(s), the concentration(s) of the preexisting xenobiotic(s) can be quantified as described before, being free from the matrix effects or recovery rates. The SAM regression equation can be expressed as $y=a x+b$, where " $a$ " is the slope of the SAM calibration curve; " $b$ " is the value of the intercept of the SAM curve on the $y$ axis, reflecting the area or height of a preexisting compound in a matrix as described before. When $y$ equals zero, $x=-b / a$, which shows the negative concentration of the preexisting compound in the tested matrix. The correlation coefficients or coefficients of determination should be greater than 0.99 within appropriate calibration range as described before, for reliable measurements of the target compounds.

\section{Limit of detection and limit of quantification}

In the SAM in the absence of blank matrices, it is, of course, impossible to create quality controls spiked with low concentrations of a target compound. Therefore, exact limits of detection (LOD) and quantification (LOQ) cannot be calculated in the same way as that of the conventional MMCM. However, there is a method to roughly estimate the LOD and LOQ; the only method is to carefully examine the height of the target compound peak in comparison with the width of fluctuating basal noise just before and after the peak. Since the concentration of the preexisting target compound had been obtained by the SAM calibration, the estimation of the concentrations based on the presumed peak heights that give the signal-to-noise $(S / N)$ ratio $=3$ (for LOD) and $S / N$ ratio $=10$ (for $L O Q$ ) can be made. If we assume that the peak 
height of a xenobiotic in a solid tissue is $33.5 \mathrm{~mm}$; the width of fluctuating noise just before and after the peak is $2.3 \mathrm{~mm}$; and the concentration of the compound has been calculated to be $24.5 \mathrm{ng} / \mathrm{g}$ wet weight, the LOD and LOQ can be calculated as follows: The $S / N$ ratio of the peak $=33.5 / 2.3=14.6$. The $\mathrm{LOD}=24.5 \mathrm{ng} / \mathrm{g} \times 3 / 14.6=5.03 \mathrm{ng} / \mathrm{g}$; the $\mathrm{LOQ}=24.5$ $\mathrm{ng} / \mathrm{g} \times 10 / 14.6=16.8 \mathrm{ng} / \mathrm{g}$. They are only the exemplifications of how to calculate them.

\section{Intraday and interday variations}

This parameter is almost equivalent to "accuracy and precision" in the MMCM. There are two procedures that we have proposed as follows. One of the below two procedures can be chosen. In our group, we are largely using the "repeatabilities" because they reflect variation ranges at the real concentration of a xenobiotic present in the corresponding matrix.

\section{Repeatabilities}

In the conventional MMCM, intraday and interday accuracies and precisions are tested by spiking low, medium and high concentrations of the target compound standard into fluid blank matrix or homogenized blank solid tissue matrix, followed by extraction and instrumental analyses. However, to make the experiment simpler and less laborious as much as possible, we propose only repetition of the quantification of the preexisting target compound in a diluted body fluid or homogenized solid tissue matrix with IS addition only using the second step procedure (see the section of "How to get concentration(s) of preexisting xenobiotic(s) in a matrix by the standard addition method"). This method includes both intraday and interday repetitive experiments. We recommend that each number of experiments is " $n=5$ " based on the literature and our own experience. We think that this method seems advantageous, because the simple intraday and interday repetition is tested to gain respective percent relative standard deviation (\%RSDs) at the actual concentration of the target compound preexisting in the matrix, which is equivalent to "precisions" in term of MMCM. A table example of the repeatability can be referred to reference [25].

\section{Modified accuracies and precisions}

The intraday and interday accuracies and precisions at low, medium and high concentrations of spiked target compound, which are currently standard in the MMCM, can be also examined in the SAM (see ref. [42] for details). Zero, low, medium and high amounts of a target compound together with a fixed amount of an IS (four points including zero addition) are spiked into the divided sample lots of each diluted liquid matrix or solid tissue homogenate all containing a preexisting xenobiotic, followed by extractions and instrumental analyses. The preexisting concentration $(D)$ (for the explanation of capital alphabet symbols " $A$ "” and " $D$ ", also see Fig. 3) of a xenobiotic can be subtracted from total concentration $\left(A^{\prime}\right)$ of the preexisting and spiked xenobiotic for all low, medium and high levels. Each net concentration to be analyzed for the target compound is $\left(A^{\prime}-D\right)$ at each concentration level, which corresponds to each spiked
Fig. 3 Images of some quantities of a preexisting or added target compound to calculate the matrix effect and recovery rate in the SAM analysis. Each quantity can be a peak area or height itself, a ratio of (peak area or height)/internal standard, or also finally calculated concentration value

\section{D: Preexisting target compound only with whole procedure including extraction}

$\mathbf{A}^{\prime}$ : Same amount as the preexisting compound spiked before extraction in the presence of preexisting compound

B': Same amount as the preexisting compound spiked after extraction in the presence of preexisting compound

C: Same amount as the preexisting compound dissolved in the reconstitution solvent without extraction (neat sample)

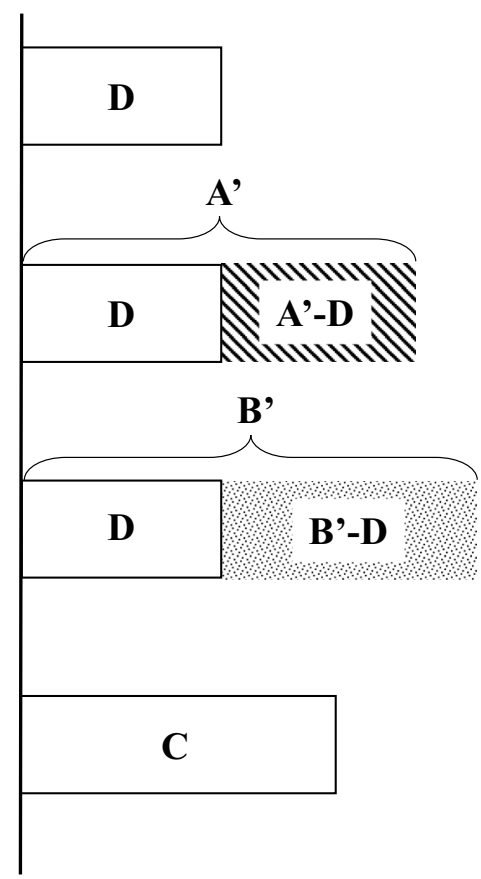


concentration in the MMCM. The "accuracy" at each level can be calculated as the percent value of $\left[\left(A^{\prime}-D\right) /(\right.$ the corresponding nominal concentration spiked) $] \times 100$. The "precision" equals to the \%RSD of triplicate or quadruplicate determinations of the net accuracy concentrations.

\section{Matrix effects and recovery rates}

Even with the absence of appropriate blank matrices, it is possible to calculate matrix effect and recovery rate in SAM. Although the SAM can overcome the matrix effects and recovery rates, the readers seem to be of interest in these parameters. Four alphabetical symbols $A^{\prime}, B^{\prime}, C$ and $D$ as the quantities specified in Fig. 3 are also used to explain the calculation of matrix effects and recovery rates by using modified procedures in SAM.

\section{Simple calculation of matrix effects and recovery rates}

For the percent matrix effect, the calculation should be $\left[\left(B^{\prime}-D\right) / C\right] \times 100$. For the percent recovery rate, it should be $\left[\left(A^{\prime}-D\right) /\left(B^{\prime}-D\right)\right] \times 100$. The symbols can be either peak areas, peak heights, the ratios of (peak area or height)/IS or also finally calculated concentration values.

\section{Relative matrix effect using standard line slope}

In the conventional MMCM, the matrix effect can be roughly estimated with the calibration line slope [10]. However, such a value obtained from slopes is less accurate than the above $\left[\left(B^{\prime}-D\right) / C\right] \times 100$ value. In the conventional method the calibration is created by spiking different amounts of a target compound into an appropriate blank matrix regardless of the presence and absence of a fixed concentration of IS. The difference of the calibration curves between the MMCM and SAM is the presence of preexisting xenobiotic(s) in SAM. Nevertheless, there will be no difference in the standard line slope. Therefore, standard line slope $(a)$ can be also used as a tentative indicator of matrix effect in SAM. To obtain the control slope $\left(a_{\mathrm{c}}\right)$ of SAM calibration equation, the matrix should be replaced by water or a mobile phase (neat solvents) for LC-MS/MS. The simple matrix effect (bias) calculation is $\left[\left(a-a_{\mathrm{c}}\right) / a_{\mathrm{c}}\right] \times 100(\%)$. The negative value obtained shows a suppressive effect, and positive one enhanced effect. Even if the ratio of a peak area against IS is employed, there is no problem, because IS values disappear during the calculation. In addition, it should be taken into mind that the relative matrix effect (bias) calculation can also be influenced by recovery rates of the assay within tested calibration range, which contributes to values of the slope.

\section{Stability}

As in the MMCM, it is preferable to present stability data also in studies and case reports using SAM. For this experiment, no quality controls (QCs: blank matrix spiked with target compound) are not necessary. The matrix containing the preexisting xenobiotic spiked or not spiked with the same compound can be used. The data are largely expressed as the percent values. The readers can follow the guideline by Peters et al. [8] in the conventional MMCM because there is essentially no big difference between the QC and original matrix containing preexisting xenobiotic in SAM (with or without spiking) for this experiment.

\section{Discussion}

In the present article, the procedures of how to conduct the SAM to quantify target xenobiotic(s) included or embedded in a matrix and of how to validate the SAM quantification in the field of forensic toxicology have been presented. Although major parameters of validations are based on the conventional MMCM, there are no guidelines focused on the details of SAM validation in the field of forensic toxicology and in other fields of analytical chemistry to our knowledge; many of the described details presented in this article are our in-house ones, which are not authorized at this time.

It should be mentioned that the word "MMCM" is not used so widely. For the calibrations by instrumental analyses, the terms "external standard calibration method", "internal standard calibration method" and "SAM" are most frequently used. Although, strictly speaking, the term "MMCM" may belong to the "external standard calibration method", but the notion of "matrix" is lacking in this term; thus the word "MMCM" seems most appropriate to use it in comparison with SAM.

As described before, the blank matrix (sometimes called "surrogate matrix") should be almost the same as or very similar to the sample matrix; however, even blood and urine samples collected from human cadavers $72 \mathrm{~h}$ or more after deaths are exactly not the same as those collected from healthy subjects due to postmortem changes such as autolysis, putrefaction and decomposition of target compound(s). Since the validation data obtained by the conventional MMCM largely depend upon QC samples composed of a blank matrix and standard compounds, the validation data do not reflect those of the sample matrix itself, but reflect those of the blank matrix. This should be kept in mind when the MMCM is used for calibration and data validation. In this respect, the SAM and its validation presented in this article exactly give the method and validation data of the sample matrix of its own. This matter can be regarded as the fourth advantage of SAM. 
As can be seen in Table 1, studies and case reports dealing with SAM tend to increase from 2012 to 2020 in forensic toxicology largely because of unavailability of the blank matrix. As stated before, it is currently mandatory to add validation data when publishing such quantitative results in an international journal. According to such trend, when the SAM had to be used, the validation data should accompany their analytical results.

As shown in Table 1 dealing with reports of quantification by SAM in forensic toxicology, we have carefully checked their details of validation data; many of the scientists appeared unfamiliar with how to create validation data for SAM. This is the reason why we tried to publish a review article on how to quantify a xenobiotic compound in an impurity-rich matrix and on how to obtain validation data, which endorse the quantification results obtained by SAM.

The outlines of 31 papers dealing with SAM in the forensic toxicology are summarized in Table 1 . The 12 out of 31 are not from our laboratories; to avoid the laboriousness to create SAM calibration curve, only three calibration points (in total, four points) were employed to make final quantification of target compound(s) with one-step calibration for seven out of the 12 papers. In the earliest paper (Table 1, No. 1), the concentration of endogenous $\gamma$-hydroxybutyrate was lower than the lowest calibration standard spiked as is the case of Fig. 2c, which might cause less accurateness in quantification. If one-step calibration is preferred, the number of calibrators should be increased to at least five (in total six points), and the resulting concentration should be inside the calibrator range.

There were relatively many SAM papers lacking validation data for eight out of the 12 papers. Furthermore, in two papers, only incomplete SAM validation data were presented. There are four papers, in which only quantifications were conducted by SAM, but the validation was performed according to the conventional MMCM. In view of these situations, it has become clear that many of the forensic toxicologists are strangers to how to create validation data for SAM.

These findings show that many of SAM papers in forensic toxicology are very problematic at this moment; the procedure of SAM quantification and its validation should be improved and standardized as soon as possible.

Such situations seem also similar in other fields of analytical chemistry from 1990s to nowadays; many papers related to SAM have appeared in environmental chemistry [57-64], food chemistry [65-68], clinical chemistry [69-71] and miscellaneous fields [72-81]. The validation approaches in non-forensic toxicology fields were also of various types like those of forensic toxicology as listed in Table 1.

Upon quantification of targeted substances in various matrices using SAM, evaluating the linearities of corresponding calibration curves should be of technical importance. In many cases of constructing calibration curves and measuring concentrations of the targeted substances using the calibrators, their calibration equations can usually be fitted to almost linear curves with a single valuable parameter using linear regression, in which correlation coefficient values being more than 0.99 within the calibration range employed; single-parameter calibration curves typically can be expressed as linear proportional function of $x$ parameter (concentration) and $y$ value (response) in measurement of target compound concentrations $(y=a x+b)$. In our experience, all 20 studies in our laboratories (Table 1) using SAM and GC-MS/LC-MS/MS gave correlation coefficients more than 0.99 and enabled the analyte concentrations with a single parameter.

However, if calibration curves contain multiple parameters with explanatory valuables, the calibration equations can demonstrate various nonlinear or polynominal curves, such as parabola $\left(y=a x_{1}{ }^{2}+b x_{2}+c\right)$ and cubic curves $\left(y=a x_{1}{ }^{3}+b x_{2}{ }^{2}+c x_{3}+d\right)$ according to each analytical condition [82]. Especially in forensic area, possible multiple parameters which can be involved in the calibration equation, are usually thought to be matrix effects and recovery rates for various kinds of matrices, or their detected signal responses in analytical instruments including LC-MS/MS [82]. Matrix effects in instrumental analysis and recovery rates in extraction procedure can vary remarkably when tested calibration range between its lower and upper levels being quite wide, because these values rely largely on either concentrations of target compounds or coeluting components in tested matrices. Therefore, the nonlinearity phenomena should also be taken into consideration upon constructing calibration curves using SAM; although such appearance of the nonlinearity when using SAM technique plus MS techniques has not been reported in the field of forensic toxicology to our knowledge, it should be kept in mind that the SAM analyses and their validations proposed in this article can be applied to real forensic toxicological quantifications only when each calibration curve is explained as a linear model. Regarding quantitative analysis by flame atomic absorption spectrometry using SAM, where calibration curves could be demonstrated as nonlinear pattern, Kościelniak [83] proposed that the more examined samples be diluted more than fivefold; the more linearity of the calibration curve might be improved, so as to fit the curves to the linear model.

On the other hand, relative narrow calibration ranges are usually employed in measurements using the SAM in forensic toxicological area. This may be one of the reasons why we neither experienced significant errors nor nonlinearity of the SAM calibration curves.

The main interest of our research group is the distribution/redistribution of toxic substances and their metabolites in various body fluids and solid tissues collected at 
autopsies. In such studies, appropriate blank specimens (surrogate matrices) are usually unavailable; we have to use the SAM for such a line of studies. The main aim of such studies is to identify the location of the body, where high concentrations of the xenobiotic or its metabolite(s) can be sampled to prove the consumption of a substance by a user and also to find the best marker(s) (largely metabolite(s)) for identifying the parent compound in question.

Finally, a new methodology called "surrogate analyte approach (SAA)" should be mentioned in comparison with the SAM [84-92]. In this method, no blank matrix is also required, but stable isotope-labeled target compound(s) is/ are essential to create calibration curve(s) and to gain validation data. All validation data of SAA do not reflect those of the blank matrix, but reflect those of sample matrix only. This is the same as that of SAM. The only disadvantage is that the stable isotope-labeled compounds are generally costly and are not available for every compound to be analyzed at the time of experiment. In the forensic toxicology field, only one paper has been published on the quantification of cocaine in street samples by the SAA in 2017, although the authors did not call it "surrogate analyte approach" [88]. Although some isotope effects on the peak areas take place for SAA, such effects can easily be corrected by using the response factor $(\mathrm{RF})$ :

$\mathrm{RF}=$ Area $_{\text {stable isotope }} /$ Area $_{\text {natural analyte }}$.

The first step experiment is also required for the SAA to estimate the level(s) of xenobiotic(s) in each matrix, which is described in the first step section of "How to get concentration(s) of preexisting xenobiotic(s) in a matrix by the standard addition method" in this article. As the second step of SAA, each solid tissue matrix or body fluid (sample matrix) all containing the target compound(s) is homogenized or diluted, respectively; a fixed concentration of IS is added to the homogenate or diluted body fluid in advance, which is then divided into ten sample lots of the same volume. Five different concentrations of the stableisotopic surrogate analyte(s) are spiked into the five sample lots, respectively, to construct calibration curve(s). The linear calibration curve(s) of SAA should pass the zero point. The remaining five lots are used for conducting validation experiments also by spiking the stable isotopic surrogate analyte(s) in place of non-isotopic target standard according to guidelines for the routine MMCM methods [6-22]. In the near future, the SAA method will join the SAM in forensic toxicology analyses, because many of analytical procedures, such as screening/the first step for an unknown matrix, stable-isotopic standard addition tests for constructing calibration curve(s), pretreatment/extraction and quantitative instrumental analysis for SAA method can be performed in common with those of SAM.
Both methods can equally work in the absence of blank matrix and can overcome the matrix effects and recovery rates; in addition, both of them function complementarily to each other. The most advantageous point of the SAA is that once a calibration curve of a specific compound in a specific matrix is constructed, every level of the same compound in the same matrix can be quantified using this calibration curve and RF without constructing a new calibration curve; but the most serious weak point is that when the stable isotope-labeled target compound is not available, the experiment cannot be conducted. In contrast, to quantify a compound in a sample matrix, the SAM is almost almighty if the detailed methods described in this article are followed; the method works even in the absence of non-isotopic or isotopic IS and also in the absence of the blank matrix (surrogate matrix), but it has a disadvantage for the necessity of creating a new SAM calibration curve for every new target for quantification, which is more laborious as described before than the conventional MMCM and the SAA method.

The combination of SAA and SAM will enhance the quantitative analytical capability when many stable isotope-labeled compounds including new psychoactive substances (NPS) are available in forensic toxicology laboratories, because a majority of drug abusers are consuming multidrugs [93], some of which are quantified by SAM and some of which are quantified by SAA. Such situation seems ideal for forensic toxicologists.

\section{Conclusions}

Based on the literature search together with our experience on the quantification of toxic substances and their metabolites by SAM, we have presented a review article on how to quantify a preexisting compound in a matrix by SAM, on advantages and disadvantages of SAM, and on how to present validation data for SAM without using the blank matrix. In addition, we have introduced 31 articles relating to quantification of toxic/abused compounds preexisting in matrices using SAM, published from 2012 to 2020. Because SAM is becoming an indispensable tool for quantification of xenobiotic(s) in a matrix especially when a blank matrix, or an appropriate IS is not available, and when distribution of a toxic compound and its metabolites over quite different matrices (body fluids and solid tissues of different components) of cadaver is studied, this article seems to serve as timely guidelines for utilizing SAM; this kind of review has not been published elsewhere to our knowledge. 


\section{Declarations}

Conflict of interest The authors have no financial or other relations that could lead to a conflict of interest.

Ethical approval This article does not contain any studies with human participants or animals performed by any of the authors.

Open Access This article is licensed under a Creative Commons Attribution 4.0 International License, which permits use, sharing, adaptation, distribution and reproduction in any medium or format, as long as you give appropriate credit to the original author(s) and the source, provide a link to the Creative Commons licence, and indicate if changes were made. The images or other third party material in this article are included in the article's Creative Commons licence, unless indicated otherwise in a credit line to the material. If material is not included in the article's Creative Commons licence and your intended use is not permitted by statutory regulation or exceeds the permitted use, you will need to obtain permission directly from the copyright holder. To view a copy of this licence, visit http://creativecommons.org/licenses/by/4.0/.

\section{References}

1. Burns DT, Walker MJ (2019) Origins of the method of standard additions and of the use of an internal standard in quantitative instrumental chemical analyses. Anal Bioanal Chem 411:27492753. https://doi.org/10.1007/s00216-019-01754-w

2. Kelly WR, Pratt KW, Guthrie WF, Martin KR (2011) Origin and early history of Die Methode des Eichzusatzes or The Method of Standard Addition with primary emphasis on its origin, early design, dissemination, and usage of terms. Anal Bioanal Chem 400:1805-1812. https://doi.org/10.1007/s00216-011-4908-4

3. Bader M (1980) A systemic approach to standard addition methods in instrumental analysis. J Chem Educ 57:703-706. https:// doi.org/10.1021/ed057p703

4. Siek TJ, Dunn WA (1993) Documentation of a doxylamine overdose death: quantitation by standard addition and use of three instrumental techniques. J Forensic Sci 38:713-720. https://doi. org/10.1520/JFS13460J

5. Poklis A, Poklis LL, Trautman D, Treece C, Backer R, Harvey CM (1998) Disposition of valproic acid in a case of fatal intoxication. J Anal Toxicol 22:537-540. https://doi.org/10.1093/jat/22.6.537 (open access article)

6. The Commission of the European Communities (2002) Commission Decision of 12 August 2002: implementing Council Directive 96/23/EC concerning the performance of analytical methods and the interpretation of results. Official Journal of the European Communities L 221: 8-36. Brussels, Belgium

7. Matuszewski BK, Constanzer ML, Chavez-Eng CM (2003) Strategies for the assessment of matrix effect in quantitative bioanalytical methods based on HPLC-MS/MS. Anal Chem 75:3019-3030. https://doi.org/10.1021/ac020361s

8. Shabir GA (2003) Validation of high-performance liquid chromatography methods for pharmaceutical analysis: understanding the differences and similarities between validation requirements of the US Food and Drug Administration, the US Pharmacopeia and the International Conference on Harmonization. J Chromatogr A 987:57-66. https://doi.org/10.1016/S0021-9673(02)01536-4

9. Taverniers I, De Loose M, Van Bockstaele E (2004) Trends in quality in the analytical laboratory. II. Analytical method validation and quality assurance. Trends Analyt Chem 23:535552. https://doi.org/10.1016/j.trac.2004.04.001

10. Matuszewski BK (2006) Standard line slopes as a measure of a relative matrix effect in quantitative HPLC-MS bioanalysis. $\mathbf{J}$ Chromatogr B 830:293-300. https://doi.org/10.1016/j.jchromb. 2005.11.009

11. Peters FT, Drummer OH, Musshoff F (2007) Validation of new methods. Forensic Sci Int 165:216-224. https://doi.org/10.1016/j. forsciint.2006.105.021

12. González AG, Herrador MÁ (2007) A practical guide to analytical method validation, including measurement uncertainty and accuracy profiles. Trends Analyt Chem 26:227-238. https://doi.org/ 10.1016/j.trac.2007.01.009

13. Jones BR, Schultz GA, Eckstein JA, Ackermann BL (2012) Surrogate matrix and surrogate analyte approaches for definitive quantitation of endogenous biomolecules. Bioanalysis 4:2349-2356. https://doi.org/10.4155/BIO.12.200

14. Scientific Working Group for Forensic Toxicology (2013) Scientific Working Group for Forensic Toxicology (SWGTOX): standard practices for method validation in forensic toxicology. J Anal Toxicol 37:452-474. https://doi.org/10.1093/jat/bkt054 (open access article)

15. Eurachem (2014) The fitness for purpose of analytical methods: a laboratory guide to method validation and related topics. https:// www.eurachem.org/images/stories/Guides/pdf/MV_guide_2nd_ ed_EN.pdf. Accessed 23 Dec 2020

16. Andersen JET (2017) The standard addition method revisited. Trends Analyt Chem 89:21-33. https://doi.org/10.1016/j.trac. 2016.12.013

17. European Commission (2017) Guidance document on analytical quality control and method validation procedures for pesticide residues and analysis in food and feed. https://ec.europa.eu/food/ sites/food/files/plant/docs/pesticides_mrl_guidelines_wrkdoc_ 2017-11813.pdf. Accessed 27 Dec 2020

18. Zhou W, Yang S, Wang PG (2017) Matrix effects and application of matrix effect factor. Bioanalysis 9:1839-1844. https://doi.org/ 10.4155/bio-2017-0214 (open access article)

19. Wakamatsu A, Ochiai S, Suzuki E, Yokota Y, Ochiai M, Kotani Y, Sasahara S, Nakanaga K, Hashimoto Y, Ueno S, Kato N, Kawada S, Hayakawa J, Shimada E, Horita S, Sakai K (2018) Proposed selection strategy of surrogate matrix to quantify endogenous substances by Japan Bioanalysis Forum DG2015-15. Bioanalysis 10:1349-1360. https://doi.org/10.4155/bio-2018-0105 (open access article)

20. U.S. Food and Drug Administration (2018) Bioanalytical method validation: guidance for industry. https://www.fda.gov/files/drugs/ published/Bioanalytical-Method-Validation-Guidance-for-Indus try.pdf. Accessed 23 Jul 2020

21. Nelis M, Augustijns P, Cabooter D (2019) Strategies for the quantification of endogenously present small molecules in biological samples. LCGC Europe 32:354-363. LCGC-07-01-2019 (open access article)

22. Cortese M, Gigliobianco MR, Magnoni F, Censi R, Di Martino P (2020) Compensate for or minimize matrix effects? Strategies for overcoming matrix effects in liquid chromatography-mass spectrometry technique: a tutorial review. Molecules 25:3047. https:// doi.org/10.3390/molecules25133047 (open access article)

23. Wurita A, Suzuki O, Hasegawa K, Gonmori K, Minakata K, Yamagishi I, Nozawa H, Watanabe K (2013) Sensitive determination of ethylene glycol, propylene glycol and diethylene glycol in human whole blood by isotope dilution gas chromatography-mass spectrometry, and the presence of appreciable amounts of the glycols in blood of healthy subjects. Forensic Toxicol 31:272-280. https://doi.org/10.1007/s11419-013-0188-3

24. Ehlers A, Morris C, Krasowski MD (2013) A rapid analysis of plasma/serum ethylene and propylene glycol by headspace gas 
chromatography. Springerplus 2: 203. http://www.springerplus. com/content $/ 2 / 1 / 203$ (open access article)

25. Wurita A, Hasegawa K, Minakata K, Gonmori K, Nozawa H, Yamagishi I, Suzuki O, Watanabe K (2014) Postmortem distribution of $\alpha$-pyrrolidinobutiophenone in body fluids and solid tissues of a human cadaver. Leg Med 16:241-246. https://doi.org/ 10.1016/j.legalmed.2014.05.001

26. Wurita A, Suzuki O, Hasegawa K, Gonmori K, Minakata K, Yamagishi I, Nozawa H, Watanabe K (2014) Presence of appreciable amounts of ethylene glycol, propylene glycol, and diethylene glycol in human urine of healthy subjects. Forensic Toxicol 32:39-44. https://doi.org/10.1007/s11419-013-0206-5

27. Wurita A, Suzuki O, Hasegawa K, Gonmori K, Minakata K, Yamagishi I, Nozawa H, Watanabe K (2014) Occurrence of postmortem production of ethylene glycol and propylene glycol in human specimens. Forensic Toxicol 32:162-168. https://doi.org/ 10.1007/s11419-013-0210-9

28. Hasegawa K, Suzuki O, Wurita A, Minakata K, Yamagishi I, Nozawa H, Gonmori K, Watanabe K (2014) Postmortem distribution of $\alpha$-pyrrolidinovalerophenone and its metabolite in body fluids and solid tissues in a fatal poising case measured by LCMS-MS with the standard addition method. Forensic Toxicol 32:225-234. https://doi.org/10.1007/s11419-014-0227-8

29. Hasegawa K, Wurita A, Minakata K, Gonmori K, Nozawa H, Yamagishi I, Suzuki O, Watanabe K (2014) Identification and quantitation of a new cathinone designer drug PV9 in an "aroma liquid" product, antemortem whole blood and urine specimens, and a postmortem whole blood specimen in a fatal poisoning case. Forensic Toxicol 32:243-250. https://doi.org/10.1007/ s11419-014-0230-0

30. Wurita A, Hasegawa K, Minakata K, Watanabe K, Suzuki O (2014) A large amount of new designer drug diphenidine coexisting with a synthetic cannabinoid 5-fluotro-AB-PINACA found in a dubious herbal product. Forensic Toxicol 32:331-337. https:// doi.org/10.1007/s11419-014-0240-y

31. Hasegawa K, Wurita A, Minakata K, Gonmori K, Nozawa H, Yamagishi I, Watanabe K, Suzuki O (2015) Postmortem distribution of AB-CHMINACA, 5-fluoro-AMB, and diphenidine in body fluids and solid tissues in a fatal poisoning case: usefulness of adipose tissue for detection of the drugs in unchanged forms. Forensic Toxicol 33:45-53. https://doi.org/10.1007/s11419-014-0245-6

32. Hasegawa K, Wurita A, Minakata K, Gonmori K, Yamagishi I, Nozawa H, Watanabe K, Suzuki O (2015) Identification and quantitation of 5-fluoro-ADB, one of the most dangerous synthetic cannabinoids, in the stomach contents and solid tissues of a human cadaver and in some herbal products. Forensic Toxicol 33:112-121. https://doi.org/10.1007/s11419-014-0259-0

33. Hasegawa K, Wurita A, Minakata K, Gonmori K, Nozawa H, Yamagishi I, Watanabe K, Suzuki O (2015) Postmortem distribution of PV9, a new cathinone derirative, in human solid tissues in a fatal poisoning case. Forensic Toxicol 33:141-147. https://doi. org/10.1007/s11419-014-0262-5

34. Hasegawa K, Wurita A, Minakata K, Gonmori K, Nozawa H, Yamagishi I, Watanabe K, Suzuki O (2015) Postmortem distribution of MAB-CHMINACA in body fluids and solid tissues of a human cadaver. Forensic Toxicol 33:380-387. https://doi.org/10. 1007/s11419-015-0272-y (open access article)

35. Hasegawa K, Wurita A, Minakata K, Gonmori K, Nozawa H, Yamagishi I, Watanabe K, Suzuki O (2015) Postmortem distribution of flunitrazepam and its metabolite 7-aminoflunitrazepam in body fluids and solid tissues in an autopsy case: usefulness of bile for their detection. Leg Med 17:394-400. https://doi.org/10. 1016/j.legalmed.2015.06.002

36. Minakata K, Yamagishi I, Nozawa H, Hasegawa K, Gonmori K, Suzuki M, Wurita A, Suzuki O (2016) Semiquantitation of diphenidine in tissue sections obtained from a human cadaver in a poisoning case by direct MALDI-QTOF mass spectrometry. Forensic Toxicol 34:151-157. https://doi.org/10.1007/ s11419-015-0300-y

37. Wurita A, Hasegawa K, Minakata K, Gonmori K, Nozawa H, Yamagishi I, Suzuki O, Watanabe K (2016) Postmortem redistribution of methamphetamine and amphetamine in blood specimens from various blood vessels and in the specimens from pericardial fluid, bile, stomach contents and various solid tissues collected from a human cadaver. Forensic Toxicol 34:191-198. https://doi. org/10.1007/s11419-015-0303-8

38. Yamagishi I, Minakata K, Nozawa H, Hasegawa K, Suzuki M, Kitamoto T, Suzuki O, Watanabe K (2018) A case of intoxication with a mixture of synthetic cannabinoids EAM-2201, ABPINACA and AB-FUBINACA, and a synthetic cathinone $\alpha$-PVP. Leg Med 35:44-49. https://doi.org/10.1016/j.legalmed.2018.08. 004

39. Hasegawa K, Wurita A, Nozawa H, Yamagishi I, Minakata K, Watanabe K, Suzuki O (2018) Fatal zolpidem poisoning due to its intravenous self-injection: postmortem distribution/redistribution of zolpidem and tis predominant metabolite zolpidem phenyl4-carboxylic acid in body fluids and solid tissues in an autopsy case. Forensic Sci Int 290:111-120. https://doi.org/10.1016/j.forsc iint.2018.06.044

40. Wurita A, Hasegawa K, Konno K, Hashimoto K, Gonmori K, Minakata K, Nozawa H, Yamagishi I, Watanabe K, Suzuki O (2019) Quantification of clitidine in caps and stems of poisonous mushroom Paralepistopsis acromelalga by hydrophilic interaction liquid chromatography-tandem mass spectrometry. Forensic Toxicol 37:378-386. https://doi.org/10.1007/s11419-019-00470-5

41. Wurita A, Hasegawa K, Nozawa H, Yamagishi I, Minakata K, Watanabe K, Suzuki O (2020) Postmortem distribution/redistribution of buformin in body fluids and solid tissues in an autopsy case using liquid chromatography-tandem mass spectrometry with QuEChERS extraction method. Forensic Sci Int 314:110376. https://doi.org/10.1016/j.forsciint.2020.110376

42. Minakata K, Hasegawa K, Nozawa H, Yamagishi I, Suzuki M, Kitamoto T, Suzuki O, Watanabe K (2020) Quantification of major metabolites of AB-FUBINACA in solid tissues obtained from its abuser. J Anal Toxicol. https://doi.org/10.1093/jat/bkaa1 20 [ahead of print]

43. Juhascik MP, Jenkins AJ (2011) Comparison of tissue homogenate analytical results with and without standard addition. J Anal Toxicol 35:179-182. https://doi.org/10.1093/anatox/35.3.179 (open access article)

44. Lehmann S, Schulze B, Thomas A, Kamphausen T, Thevis M, Rothschild MA, Mercer-Chalmers-Bender K (2018) Organ distribution of 4-MEC, MDPV, methoxetamine and $\alpha$-PVP: comparison of QuEChERS and SPE. Forensic Toxicol 36:320-333. https://doi. org/10.1007/s11419-018-0408-y

45. Gergov M, Nenonen T, Ojanperä I, Ketola RA (2015) Compensation of matrix effects in a standard addition method for metformin in postmortem blood using liquid chromatography-electrospraytandem mass spectrometry. J Anal Toxicol 39:359-364. https:// doi.org/10.1093/jat/bkv020 (open access article)

46. Cheng S-Y, Ng-A-Qui T, Eng B, Ho J (2017) Detection of cathinone mephedrone in plasma by LC-MS/MS using standard addition quantification technique. J Anal Sci Technol 8:19. https://doi. org/10.1186/s40543-017-0128-7 (open access article)

47. Ivanov ID, Stoykova S, Ivanova E, Vlahova A, Burdzhiev N, Pantcheva I, Atanasov VN (2019) A case of 5F-ADB/FUB-AMB abuse: drug-induced or drug-related death? Forensic Sci Int 297:372-377. https://doi.org/10.1016/j.forsciint.2019.02.005

48. Bertol E, Argo A, Procaccianti P, Vaiano F, Di Milia MG, Furlanetto S, Mari F (2012) Detection of gamma-hydroxybutyrate in hair: validation of GC-MS and LC-MS/MS methods and 
application to a real case. J Pharm Biomed Anal 70:518-522. https://doi.org/10.1016/j.jpba.2012.07.009

49. Poklis JL, Devers KG, Arbefeville EF, Pearson JM, Houston E, Poklis A (2013) Postmortem detection of 25I-NBOMe [2-(4-iodo2,5-dimethoxyphenyl]-N-[(2-methoxyphenyl)methyl]ethanamine] in fluids and tissues determined high performance liquid chromatography with tandem mass spectrometry from a traumatic death. Forensic Sci Int 234:e14-e20. https://doi.org/10.1016/j.forsciint. 2013.10.015

50. Carlier J, Romeuf L, Guitton J, Briez-Barallon C, Bévalot F, Fanton L, Gaillard Y (2014) A validated method for quantifying atractyloside and carboxyatractyloside in blood by HPLC-HRMS/ MS, a non-fatal case of intoxication with Atractylis gummifera L. J Anal Toxicol 38:619-627. https://doi.org/10.1093/jat/bku078 (open access article)

51. Vaiano F, Serpelloni G, Furlanetto S, Palumbo D, Mari F, Fioravanti A, Bertol E (2016) Determination of endogenous concentration of $\gamma$-hydroxybutyric acid (GHB) in hair through an ad hoc GC-MS analysis: a study on a wide population and influence of gender and age. J Pharm Biomed Anal 118:161-166. https://doi. org/10.1016/j.jpba.2015.10.036

52. Schaefer N, Kettner M, Laschke MW, Schlote J, Ewald AH, Menger MD, Maurer HH, Schmidt PH (2017) Distribution of synthetic cannabinoids JWH-210, RCS-4 and $\Delta$ 9-tetrahydrocannabinol after intravenous administration to pigs. Curr Neuropharmacol 15:713-723. https://doi.org/10.2174/15701 59X15666161111114214

53. Schaefer N, Kröll A-K, Körbel C, Laschke MW, Menger MD, Maurer HH, Meyer MR, Schmidt PH (2019) Distribution of the (synthetic) cannabinoids JWH-210, RCS-4, as well as $\Delta$ 9-tetrahydrocannabinol following pulmonary administration to pigs. Arch Toxicol 93:2211-2218. https://doi.org/10.1007/ s00204-019-02493-8

54. Wagmann L, Manier SK, Eckstein N, Maurer HH, Meyer MR (2020) Toxicokinetic studies of the four new psychoactive substances 4-chloroethcathinone, $N$-ethylnorpentylone, $N$-ethylhexedrone, and 4-fluoro-alpha-pyrrolidinohexiophenone. Forensic Toxidol 38:59-69. https://doi.org/10.1007/s11419-019-00487-w

55. Krotulski AJ, Papsun DM, Kacinko SL, Logan BK (2020) Isotonitazene quantitation and metabolic discovery in authentic forensic casework. J Anal Toxicol 44:521-530. https://doi.org/10.1093/jat/ bkaa016

56. Mochizuki A, Nakazawa H, Adachi N, Takekawa K, Shojo H (2019) Postmortem distribution of mepirapim and acetyl fentanyl in biological fluid and solid tissue specimens measured by the standard addition method. Forensic Toxicol 37:27-33. https://doi. org/10.1007/s11419-018-0431-z (open access article)

57. Gittins CM, Castaldi MJ, Senkan SM, Rohlfing EA (1997) Realtime quantitative analysis of combustion-generated polycyclic aromatic hydrocarbons by Binici Bresonance-enhanced Multiphoton ionization time-of-flight mass spectrometry. Anal Chem 69:286-293. https://doi.org/10.1021/ac960969z

58. Huybrechts T, Dewulf J, Moerman O, Van Langenhove H (2000) Evaluation of purge-and-trap-high-resolution gas chromatography-mass spectrometry for the determination of 27 volatile organic compounds in marine water at the $\mathrm{ng} \mathrm{l}^{-1}$ concentration level. J Chromatogr A 893:367-382. https://doi.org/10.1016/ S0021-9673(00)00771-8

59. Ito S, Tsukada K (2002) Matrix effect and correction by standard addition in quantitative liquid chromatographic-mass spectrometric analysis of diarrhetic shellfish poisoning toxins. J Chromatogr A 943:39-46. https://doi.org/10.1016/S0021-9673(01)01429-7

60. Renew JE, Huang C-H (2004) Simultaneous determination of fluoroquinolone, sulfonamide, and trimethoprim antibiotics in wastewater using tandem solid phase extraction and liquid chromatography-electrospray mass spectrometry. J Chromatogr A 1042:113-121. https://doi.org/10.1016/j.chroma.2004.05.056

61. Cimetiere N, Soutrel I, Lemasle M, Laplanche A, Crocq A (2013) Standard addition method for the determination of pharmaceutical residues in drinking water by SPE-LC-MS/MS. Environ Technol 34:3031-3041. https://doi.org/10.1080/09593330.2013.800563

62. Majoros LI, Lava R, Ricci M, Binici B, Sandor F, Held A, Emons H (2013) Full method validation for the determination of hexachlorobenzene and hexachlorobutadiene in fish tissue by GCIDMS. Talanta 116:251-258. https://doi.org/10.1016/j.talanta. 2013.04.080

63. Rossmann J, Schubert S, Gurke R, Oertel R, Kirch W (2014) Simultaneous determination of most prescribed antibiotics in multiple urban wastewater by SPE-LC-MS/MS. J Chromatogr B 969:162-170. https://doi.org/10.1016/j.jchromb.2014.08.008

64. Goncalves DA, Jones BT, Donati GL (2016) The reversed-axis method to estimate precision in standard addition analysis. Microchem J 124:155-158. https://doi.org/10.1016/j.microc.2015.08. 006 (open access article)

65. Pozo-Bayon MA, Guichard E, Cayot N (2006) Feasibility and application of solvent assisted flavor evaporation and standard addition method to quantify the aroma compounds in flavoured baked matrices. Food Chem 99:416-423. https://doi.org/10. 1016/j.foodchem.2005.08.005

66. Gentili A, Caretti F (2011) Evaluation of a method based on liquid chromatography-diode array detector-tandem mass spectrometry for a rapid and comprehensive characterization of the fat-soluble vitamin and carotenoid profile of selected plant food. J Chromatogr A 1218:684-697. https://doi.org/10.1016/j.chroma.2010.12. 001

67. Viñas P, Bravo-Bravo M, López-García I, Hernández-Córdoba M (2013) Diversive liquid-liquid microextraction for the determination of vitamins $\mathrm{D}$ and $\mathrm{K}$ in foods by liquid chromatography with diode-array and atmospheric pressure chemical ionization-mass spectrometry detection. Talanta 115:806-813. https://doi.org/10. 1016/j.talanta.2013.06.050

68. Redruello B, Ledero V, del Rio B, Fernández M, Martín MC, Alvarez MA (2017) A UHPLC method for the simultaneous analysis of biogenic amines, amino acids and ammonium ions in beer. Food Chem 217:117-124. https://doi.org/10.1016/j.foodc hem. 2016.08040

69. van de Merbel NC, Mentink CJAL, Hendrikks G, Wolffenbuttel BHR (2004) Liquid chromatographic method for the quantitative determination of $N^{\mathrm{e}}$-carboxymethyllysine in human piasma proteins. J Chromatogr B 808:163-168. https://doi.org/10.1016/j. jchromb.2004.05.004

70. Lai X, Kline JA, Wang M (2015) Development, validation, and comparison of four methods to simultaneously quantify L-arginine, citrulline, and ornithine in human plasma using hydrophilic interaction liquid chromatography and electrospray tandem mass spectrometry. J Chromatogr B 1005:47-55. https://doi.org/10. 1016/j.jchromb.2015.10.001

71. Hewavitharana AK, Kassim NSA, Shaw PN (2018) Standard addition with internal standardization as an alternative to using stable isotope labelled internal standards to correct for matrix effects - comparison and validation using liquid chromatographytandem mass spectrometric assay of vitamin D. J Chromatogr A 1553:101-107. https://doi.org/10.1016/j.chroma.2018.04.026

72. Butter JJ, Koopmans RP, Michel MC (2005) A rapid and validated HPLC method to quantify sphingosine 1-phosphate in human plasma using solid-phase extraction followed by derivatization with fluorescence detection. J Chromatogr B 824:65-70. https:// doi.org/10.1016/j.jchromb.2005.06.040

73. López-Carbonell M, Jáuregui O (2005) A rapid method for analysis of abscisic acid (ABA) in crude extracts of water stressed 
Arabidopsis thaliana plants by liquid chromatography-mass spectrometry in tandem mode. Plant Physiol Biochem 43:407-411. https://doi.org/10.1016/j.plaphy.2005.02.006

74. Signor L, Varesio E, Staack RF, Starke V, Richter WF, Hopfgartner G (2007) Analysis of erlotinib and its metabolites in rat tissue sections by MALDI quadrupole time-of-flight mass spectrometry. J Mass Spectrom 42:900-909. https://doi.org/10.1002/ jms. 1225

75. Scherer M, Gnewuch C, Schmitz G, Liebisch G (2009) Rapid quantification of bile acids and their conjugates in serum by liquid chromatography-tandem mass spectrometry. J Chromatogr B 877:3920-3925. https://doi.org/10.1016/j.jchromb.2009.09.038

76. Boscher A, Guignard C, Pellet T, Hoffmann L, Bohn T (2010) Development of a multi-class method for the quantification of veterinary drug residues in feedingstuffs by liquid chromatography-tandem mass spectrometry. J Chromatogr A 1217:6394-6404. https://doi.org/10.1016/j.chroma.2010.08.024

77. Thakare R, Chhonker YS, Gautam N, Alamoudi JA, Alnouti Y (2016) Quantitative analysis of endogenous compounds. J Pharm Biomed Anal 128:426-437. https://doi.org/10.1016/j.jpba.2016. 06.017

78. Giannoulas G, Tsogas GZ, Giokas DL (2019) Single-point calibration and standard addition assays on calibrant-loaded paper-based analytical devices. Talanta 201:149-155. https://doi.org/10.1016/j. talanta.2019.04.008

79. Wu C, Sun DX, Su MG, Yin YP, Han WW, Lu QF, Dong CZ (2019) Quantitative analysis of $\mathrm{Pb}$ in soil samples by laserinduced breakdown spectroscopy with a simplified standard addition method. J Anal At Spectrom 34:1478-1484. https://doi.org/ $10.1039 / \mathrm{c} 9 \mathrm{ja00059c}$

80. Tapia MA, Pérez-Ràfols C, Ariño C, Serrano N, Díaz-Cruz JM (2020) New approach to multivariate standard addition based on multivariate curve resolution by alternating least-squares: application to voltammetric data. Anal Chem 92:3396-3402. https://doi. org/10.1021/acs.analchem.9b05477

81. Kafle B, Baak J, Brede C (2020) Quantification by LC-MS/MS of astragaloside IV and isoflavones in Astraga anali radix can be more accurate by using standard addition. Phytochem Anal. https://doi.org/10.1002/pca.2994 (open access article)

82. Asnin LD (2016) Peak measurement and calibration in chromatographic analysis. Trends Analyt Chem 81:51-62. https://doi.org/ 10.1016/j.trac.2016.01.006

83. Kościelniak P (1999) Nonlinear calibration by the standard addition method. Chemometr Intell Lab Syst 47:275-287. https://doi. org/10.1016/S0169-7439(98)00215-9

84. Ahmadkhaniha R, Shafiee A, Rastkari N, Khoshayand MR, Kobarfard F (2010) Quantification of endogenous steroids in human urine by gas chromatography mass spectrometry using a surrogate analyte approach. J Chromatogr B 878:845-852. https://doi.org/ 10.1016/j.jchromb.2010.01.040
85. Penner N, Ramanathan R, Zgoda-Pols J, Chowdhury S (2010) Quantitative determination of hippuric and benzoic acids in urine by LC-MS/MS using surrogate standards. J Pharm Biomed Anal 52:534-543. https://doi.org/10.1016/j.jpba.2010.01.016

86. Kang S, Oh SM, Chung KH, Lee S (2014) A surrogate analyte-based LC-MS/MS method for the determination of $\gamma$-hydroxybutyrate (GHB) in human urine and variation of endogenous urinary concentration of GHB. J Pharm Biomed Anal 98:193-200. https://doi.org/10.1016/j.jpba.2014.05.028

87. Binz TM, Braun U, Baumgartner MR, Kraemer T (2016) Development of an LC-MS/MS method for the determination of endogenous cortisol in hair using ${ }^{13} \mathrm{C}_{3}$-labeled cortisol as surrogate analyte. J Chromatogr B 1033-1034:65-72. https://doi.org/10. 1016/j.jchromb.2016.07.041

88. Brockbals L, Karlsen M, Ramsey J, Miserez B (2017) Single injection quantification of cocaine using multiple isotopically labeled internal standards. Forensic Toxicol 35:153-161. https:// doi.org/10.1007/s11419-016-0328-7

89. Yin F, Ling Y, Keller J, Kraus D, Narayanaswamy R, Mangus H, Li F, Yang H, Liu G (2020) Quantitation of 2-hydroxyglutarate in human plasma via LC-MS/MS using a surrogate analyte approach. Bioanalysis 12:1149-1159. https://doi.org/10.4155/bio-2020-0131

90. Yin F, Keller J, Kraus D, Mangus H, Li F, Liu G (2020) A double surrogate approach for the quantitation of 2-hydroxyglutarate-an oncometabolite in human brain tumors via LC-MS/MS. J Pharm Biomed Anal. https://doi.org/10.1016/j.jpba.2019.112916

91. Cong M, Song J, Chen F, Cao C, Wang S (2020) A surrogate analyte-based LC-MS/MS method for the determination of 5-hydroxytryptamine, kynurenine and tryptophan. Bioanalysis. https://doi.org/10.4155/bio-2019-0267

92. Voegel CD, Baumgartner MR, Kraemer T, Wüst S, Binz TM (2021) Simultaneous quantification of steroid hormones and endocannabinoids (ECs) in human hair using an automated supported liquid extraction (SLE) and LC-MS/MS - insight into EC baseline values and correlation to steroid concentrations. Talanta 222:121499. https://doi.org/10.1016/j.talanta.2020.121499 (open access article)

93. Pardi J, Toriello A, Cooper G (2020) Evaluation of 4-fluoroisobutyrylfentanyl in blood samples from 247 authentic cases submitted to the New York City Office of Chief Medical Examiner in 2017-2018. Forensic Toxicol 38:340-351. https://doi.org/10. 1007/s11419-019-00518-6

Publisher's Note Springer Nature remains neutral with regard to jurisdictional claims in published maps and institutional affiliations. 